\title{
Coastal Trapped Waves and Other Subinertial Variability along the Southeast Greenland Coast in a Realistic Numerical Simulation 0
}

\author{
Renske Gelderloos, ${ }^{\text {a }}$ Thomas W. N. Haine, ${ }^{a}$ And Mattia Almansi ${ }^{\mathrm{a}, \mathrm{b}}$ \\ ${ }^{a}$ Department of Earth and Planetary Sciences, The Johns Hopkins University, Baltimore, Maryland
}

(Manuscript received 1 October 2020, in final form 15 December 2020)

\begin{abstract}
Ocean currents along the southeast Greenland coast play an important role in the climate system. They carry dense water over the Denmark Strait sill, freshwater from the Arctic and the Greenland Ice Sheet into the subpolar ocean, and warm Atlantic Ocean water into Greenland's fjords, where it can interact with outlet glaciers. Observational evidence from moorings shows that the circulation in this region displays substantial subinertial variability (typically with periods of several days). For the dense water flowing over the Denmark Strait sill, this variability augments the time-mean transport. It has been suggested that the subinertial variability found in observations is associated with coastal trapped waves, whose properties depend on bathymetry, stratification, and the mean flow. Here, we use the output of a high-resolution realistic simulation to diagnose and characterize subinertial variability in sea surface height and velocity along the coast. The results show that the subinertial signals are coherent over hundreds of kilometers along the shelf. We find coastal trapped waves on the shelf and along the shelf break in two subinertial frequency bands-at periods of 1-3 and 5-18 days-that are consistent with a combination of mode-I waves and higher modes. Furthermore, we find that northeasterly barrier winds may trigger the 5-18-day shelf waves, whereas the 1-3-day variability is linked to high wind speeds over Sermilik Deep.
\end{abstract}

KEYWORDS: Boundary currents; Wave properties; Oceanic variability

\section{Introduction}

The Southeast Greenland shelf/slope region harbors several processes that are important for the climate system. Dense water spills over the relatively shallow sill in the Denmark Strait, feeding the lower limb of the Atlantic meridional overturning circulation (AMOC); warm Atlantic Ocean water spills into the Greenlandic fjords and interacts with the ice sheet's outlet glaciers. Observations show that both processes display substantial subinertial variability - that is, variations with a time scale of several days. The primary focus of research on the regional circulation in this region has been on long-term mean quantities, but evidence suggests that subinertial variability affects the mean state significantly: boluses and pulses increase the dense overflow transport in the Denmark Strait by 30\% (Almansi et al. 2017), and warm Atlantic water enters the fjords in this region at quasi-periodic time intervals (Jackson et al. 2014, 2018). Subinertial variability along the shelf break could also play an important role in shelf-basin exchange by providing a possible driving mechanism for downwelling along the shelf, which is where the net sinking in the AMOC takes place (Katsman et al. 2018). Understanding and quantifying the processes associated with subinertial variability is thus essential for understanding the mean flow.

Supplemental information related to this paper is available at the Journals Online website: https://doi.org/10.1175/JPO-D-200239.s1.

\footnotetext{
${ }^{\mathrm{b}}$ Current affiliation: National Oceanography Centre, Southampton, United Kingdom.
}

Corresponding author: Renske Gelderloos, rgelder2@jhu.edu
Several studies have found subinertial variability in this region. The most well-known source of subinertial variability is the Denmark Strait Overflow, which produces coherent eddies ("DSO eddies") that move dense water downstream from the sill (Jochumsen et al. 2017; Almansi et al. 2017, 2020), and have an imprint on the sea surface temperature (Bruce 1995). Subinertial variability also occurs at the shelf break and on the shelf (von Appen et al. 2014a; Harden and Pickart 2018), and in fjord-shelf exchange flows (Jackson et al. 2014, 2018; Fraser and Inall 2018; Fraser et al. 2018; Spall and Pedlosky 2018). The subinertial variations in observations have shown some coherence between moorings at different along-shelf locations, sparking the hypothesis that this variability could be associated with coastal trapped waves (CTWs; Harden et al. 2014b; Jochumsen et al. 2017). The small dynamical length scales at high latitudes and the rapid variations in along-shelf bathymetry and the presence of fjords make observing these phenomena challenging. Using a realistic high-resolution model, however, enables us to identify and categorize a variety of subinertial oscillations as well as their spatial structure. This work will help to put in situ observations into a wider spatial and temporal perspective and lay the groundwork for a further dynamical understanding of these phenomena.

The field of CTWs goes back to early work by Robinson (1964) (although work on internal Kelvin waves predates that paper), who aimed to find an explanation for the deviation of sea surface height variations from the inverse barometer effect in measurements by Hamon $(1962,1963)$ on the Australian continental shelf. In the next decades, studies expanded on this work by considering the combined effects of sloping bathymetry and stratification in both free and forced wave problems from a theoretical perspective (Mysak 1967a,b; Buchwald and Adams 1968; Adams and Buchwald 1969; 


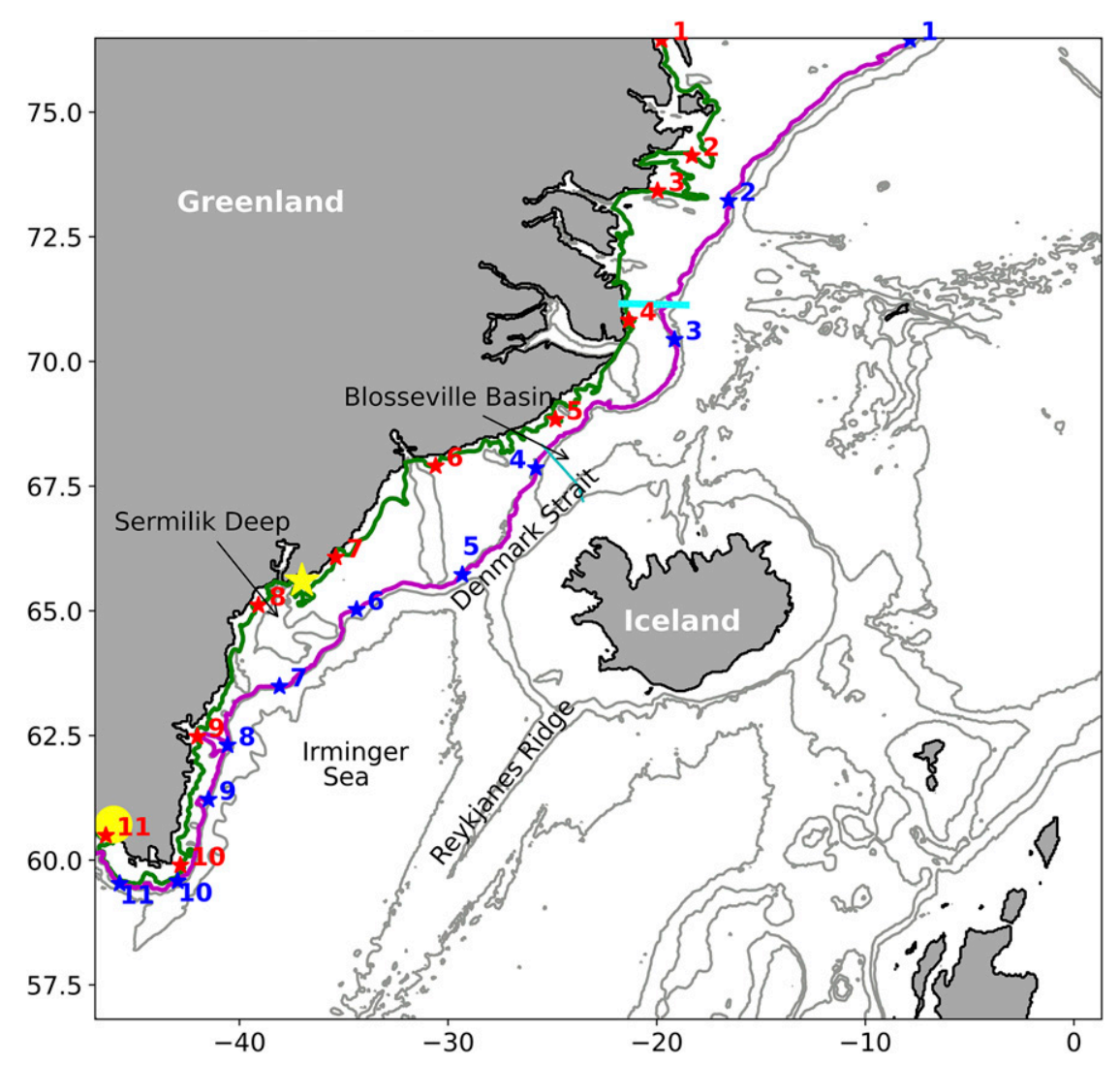

FIG. 1. Map of the study region. Landmasses are gray. Bathymetry is contoured at 400-, 1000-, and 2000-m depth. The 200-m isobath along the Greenland coast is indicated in green. Note that the contour has been artificially altered to skip the fjords when interpolation near the coast inside these fjords would yield large data gaps. The magenta contour is the 450-m isobath along the Greenland coast. The thick cyan line is the cross-shelf section used in section $4 \mathrm{~d}$. The thin cyan line is the Kögur section (see also Fig. 2). The yellow star is the location of the Ammassalik tide gauge, and the yellow solid circle is the location of the Qaqortoq tide gauge. Red and blue stars are stations along the isobaths used in the text. Geographical locations in the ocean referenced in the text are indicated in black-font text.

Rhines 1970), laboratory experiments (Caldwell et al. 1972), and in situ observations (Mooers and Smith 1968; Cutchin and Smith 1973; Clarke 1977). The term "coastal trapped waves"- a hybrid between barotropic continental shelf waves, which are impacted by bathymetry [the ones studied by Robinson (1964)], and internal Kelvin waves, which are impacted by stratification-first appears in Gill and Clarke (1974). Reviews on the topic can be found in Mysak (1980), Huthnance (1978), and Brink (2006).

More recently, research on CTWs has benefited from more observational evidence (Inall et al. 2015) and more realistic simulations (Fraser and Inall 2018; Fraser et al. 2018). Observational evidence for subinertial variability is plentiful on the East Greenland shelf and slope (e.g., von Appen et al. 2014a; Harden et al. 2014a,b; Jackson et al. 2014; Fischer et al. 2015; Harden et al. 2016; Harden and Pickart 2018; Bras et al. 2018; Pacini et al. 2020). However, the characteristics of this variability and its relationship to CTWs are still open questions.
The objectives of this paper are thus to show that (i) subinertial variability along the southeast Greenland coast is coherent along and across the continental shelf, and that (ii) the characteristics of this variability are consistent with CTWs. We find that the signal around the Denmark Strait deviates from the signals found upstream and downstream of the sill. The behavior at the sill indicates nonlinear steepening of propagating waves and interaction with waves propagating around Iceland. Although this behavior is interesting and should be studied, it is beyond the scope of this paper. Our focus is on investigating coherence between signals upstream and downstream of the sill region.

This paper is structured as follows: section 2 contains a brief description of the setup of the numerical model used in this study, and some time mean quantities are discussed in section 3. In section 4, subinertial variability is diagnosed and characterized, is shown to be coherent along the southeast Greenland coast, and is shown to be associated with CTWs. Section 5 shows that some of the variability is 

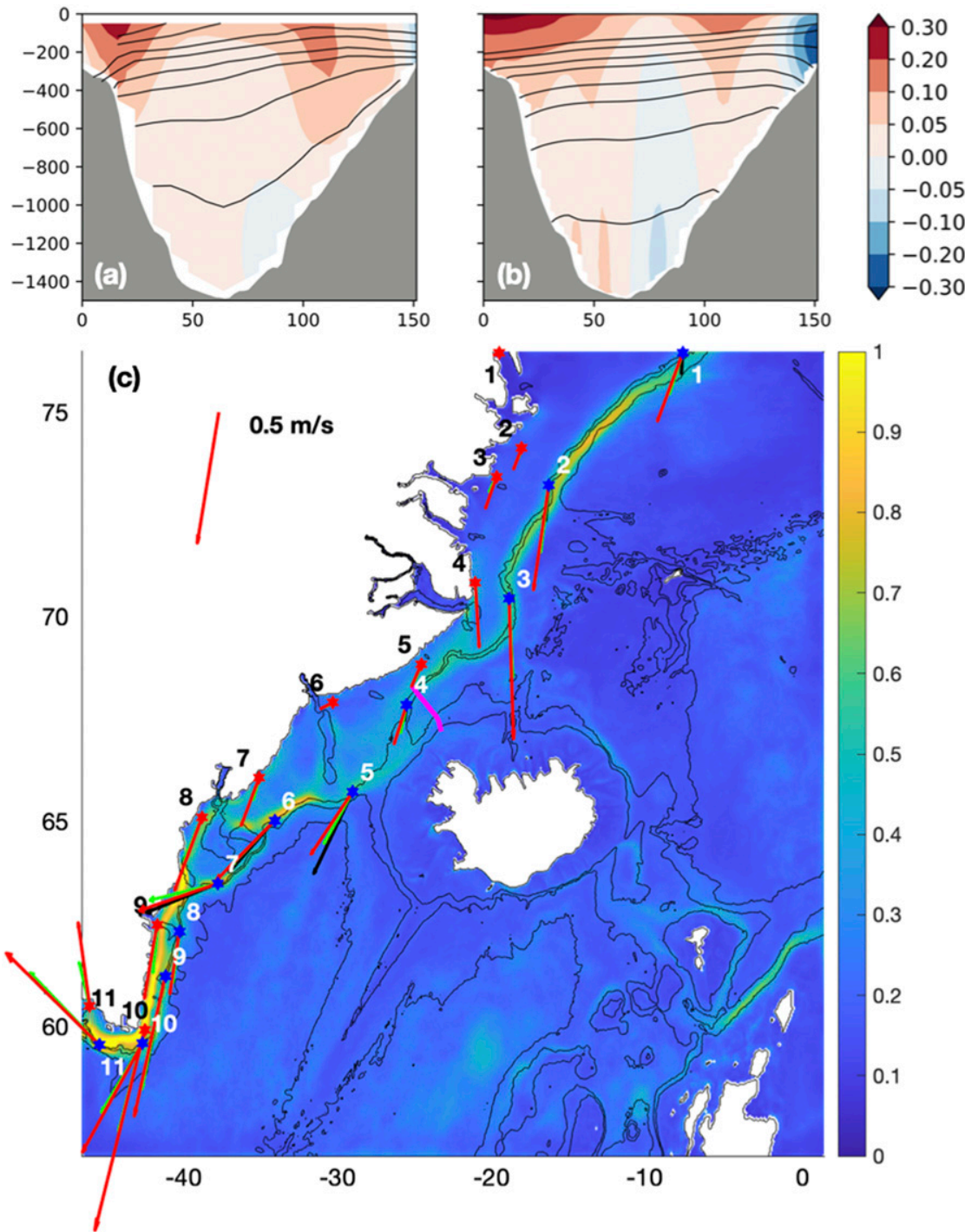

FIG. 2. Mean velocity: the annual mean velocity orthogonal to the Kögur section [magenta line in (c)] from (a) in situ observations in 2011-12 (Harden et al. 2016) and (b) the model mean from 2007 to 2008; positive values $\left(\mathrm{m} \mathrm{s}^{-1}\right)$ are toward the equator. Contoured in gray is potential density (contour levels are 27.3, 27.5, 27.7, 27.8, 27.9, 27.95, 28.0, and $28.05 \mathrm{~kg} \mathrm{~m}^{-3}$ ). (c) Mean surface current speed (filled contours; $\mathrm{m} \mathrm{s}^{-1}$ ) and mean current vectors as a function of depth (red arrows: top 50 m; green arrows: 50-200-m average; black arrows: $>200$-m average) at the shelf (red stars; black numbers) and shelfbreak (blue stars; white numbers) stations (see also Fig. 1). The 450-, 1000-, and 2000-m isobaths are contoured in black in (c).

forced by wind events. Conclusions from this work are presented in section 6 .

\section{Numerical model}

We use a high-resolution regional ocean-sea ice configuration of the primitive equation Massachusetts Institute of Technology general circulation model (MITgcm; Marshall et al. 1997). The setup is identical to the one used by Almansi et al. (2020) and was not specifically designed to study waves. The main characteristics of the setup are summarized below; for details the reader is referred to Almansi et al. (2017, 2020). For extraction of model fields on hydrographic sections, along mooring arrays, and along isobaths we use the open-source software package OceanSpy (Almansi et al. 2019), and for the data analysis we use jLab (Lilly 2019).

The model domain is centered around the Denmark Strait and includes the Southeast Greenland shelf region, the entire Greenland-Scotland Ridge, the Irminger and Iceland Seas, the 

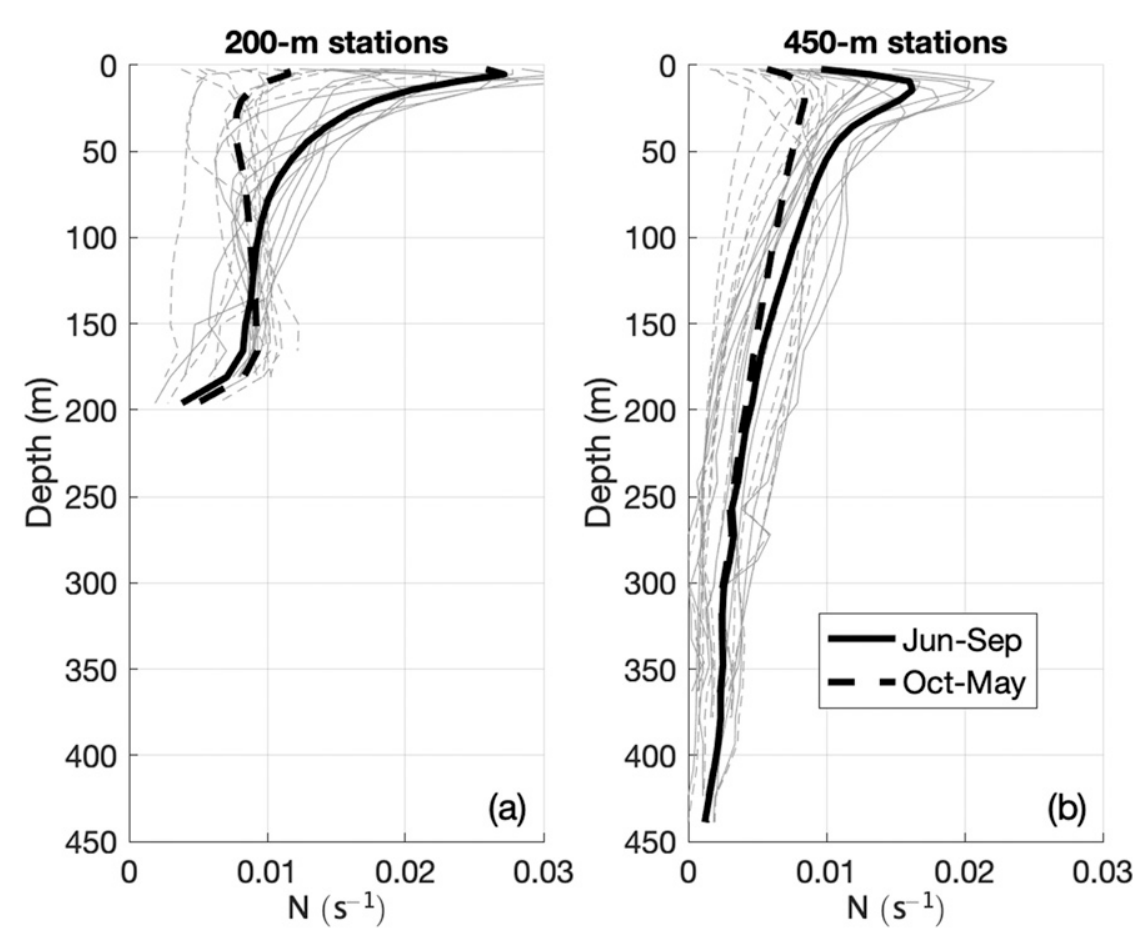

FIG. 3. Vertical density stratification quantified with the buoyancy frequency $N$. Solid lines are summer profiles (June-September); dashed lines are winter profiles (October-May). The gray profiles are individual stations, and the thick profiles are averages over all 11 stations along the (a) 200- and (b) 450-m isobaths.

Iceland Basin, and parts of the Greenland and Norwegian Basins (Fig. 1). The model is run in hydrostatic mode with 216 vertical levels, ranging from $2 \mathrm{~m}$ at the surface to $15 \mathrm{~m}$ below $120-\mathrm{m}$ depth. The horizontal resolution is $2 \mathrm{~km}$ around the Denmark Strait, decreasing to $4 \mathrm{~km}$ near the boundaries of the domain. The model was run for 1 year from September 2007 to August 2008, after an initial 8-month spinup as described by Almansi et al. (2017), and snapshots of the fields were stored every $6 \mathrm{~h}$. At the open boundaries, tracer values and velocities are nudged toward daily HYCOM+NCODA $1 / 12^{\circ}$ global reanalysis fields (Cummings and Smedstad 2013). Sea surface temperatures are relaxed to the Operational Sea Surface Temperature and Sea Ice Analysis (OSTIA) global product (Donlon et al. 2012), and atmospheric forcing is provided by the 3-hourly $15-\mathrm{km}$ Arctic System Reanalysis (ASRv2; Bromwich et al. 2018). The boundary and surface forcing fields are linearly interpolated in time by the MITgcm before they are applied. This model setup has no tidal forcing.

The ocean model is coupled to a viscous plastic dynamic/thermodynamic sea ice model (Losch et al. 2010; Heimbach et al. 2010) with the subgrid-scale salt plume parameterization (Nguyen et al. 2009). Sea ice values are nudged over 20 grid points from the open boundaries to the monthly $1 / 8^{\circ}$ Toward an Operational Prediction System for the North Atlantic European Coastal Zone reanalysis, version 4 (TOPAZv4; Sakov et al. 2012). Freshwater forcing from the Greenland ice sheet is based on Noël et al. (2016) for surface runoff and Bamber et al. (2012) for solid-ice discharge.

\section{Mean flow and stratification along the shelf in the numerical model}

This model setup and previous versions of the same setup have been shown to realistically simulate the ocean circulation in the greater Denmark Strait region (Haine 2010; Magaldi et al. 2011; Koszalka et al. 2013; von Appen et al. 2014b; Gelderloos et al. 2017; Almansi et al. 2017; Håvik et al. 2019; Almansi et al. 2020; Saberi et al. 2020; Foukal et al. 2020). We focus here on the time-mean current and density fields (the mean SSH has no impact on wave dynamics, unlike the mean flow and stratification and is therefore not discussed; note that $\mathrm{SSH}$ variability, on the other hand, is crucial and will be discussed in the next section) at 11 roughly equally spaced stations along the $200-\mathrm{m}$ isobath and at 11 stations also roughly equally spread out along the 450-m isobath (red and blue stars in Fig. 1, respectively). The 200-m isobath (green contour in Fig. 1) hugs the coast, while the 450-m isobath (magenta contour in Fig. 1) roughly delineates the shelf break along the southeast Greenland coast within the model domain.

Before looking at the velocity structure along the coast, we compare the velocity across a single section at the Kögur line (magenta line in Fig. 2c) with available observations. Figure 2a shows the velocity from a gridded product based on moored instrument measurements in 2011-12 (Harden et al. 2016), and 

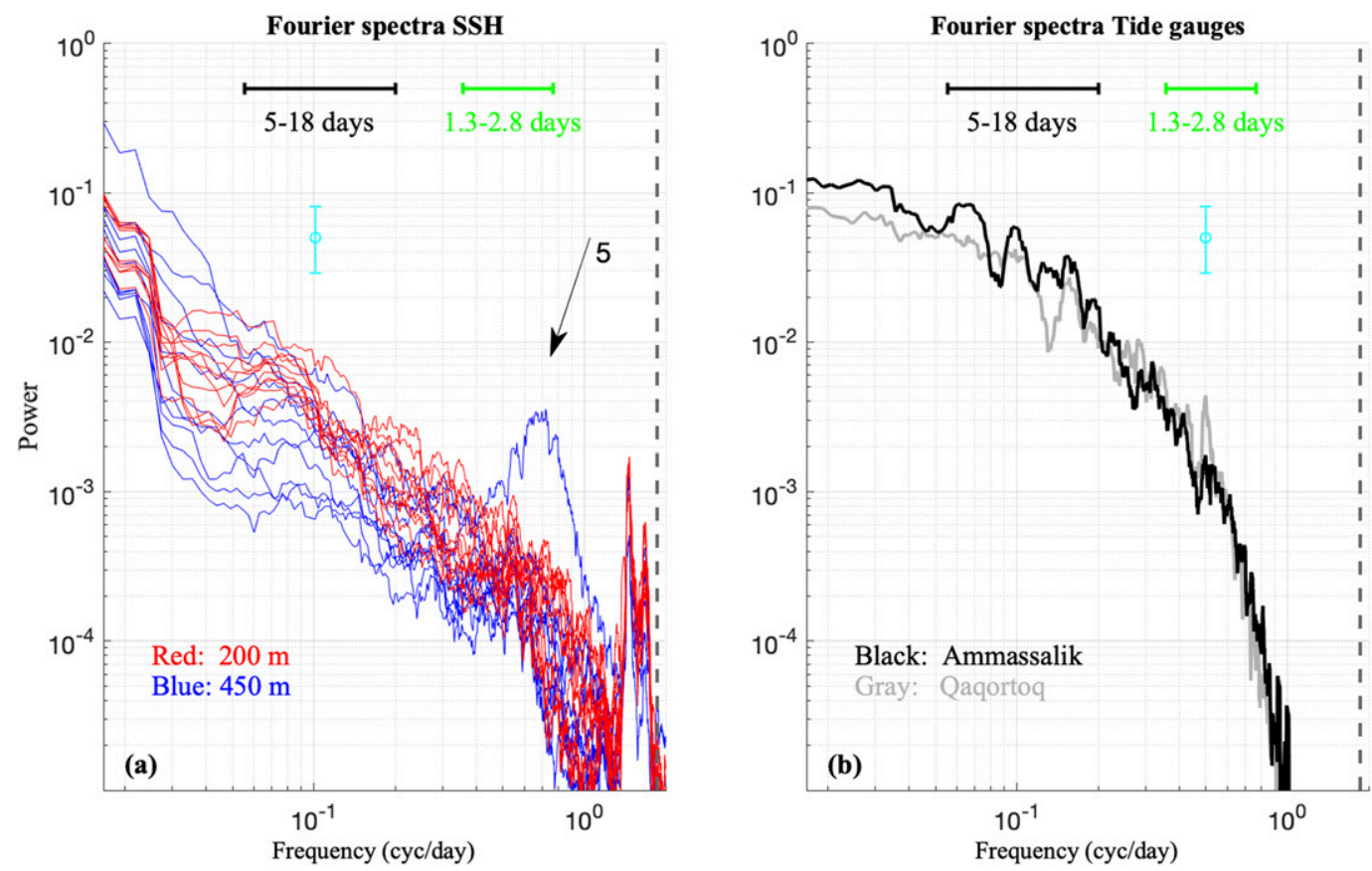

FIG. 4. Fourier frequency spectrum estimates for SSH: (a) Spectra for SSH anomalies at 11 stations along the 200-m isobath (red lines; red stars in Fig. 1) and 11 stations along the 450-m isobath (blue lines; blue stars in Fig. 1). The curve labeled " 5 " corresponds to station 5 on the 450-m isobath, i.e., the station just downstream of the Denmark Strait sill. The gray vertical dashed line indicates the inertial frequency at $68^{\circ} \mathrm{N}$. The horizontal bars are two frequency ranges, annotated in days. The vertical cyan bar indicates $95 \%$ confidence limits. (b) Spectral estimates from tide gauges at Ammassalik (black curve) and Qaqortoq (gray curve). See Fig. 1 for the locations of these tide gauges.

Fig. 2b shows its model counterpart. The model captures the magnitude and location of the shelfbreak current maximum (around $20 \mathrm{~km}$ ) well. The model core is wider than in observations, but the Greenland shelf was sparsely sampled by the moorings and the agreement on the shelf is still very good compared to densely sampled hydrographic surveys (see Fig. 2 in Foukal et al. 2020). The mean velocity vectors for the 22 coastal and shelf break stations are plotted for three depth ranges in Fig. 2c. The mean flow at all stations is along the coast in a southwesterly direction, consistent with observations. The large mean velocities along the shelf break are due to the shelfbreak jet called the East Greenland Current (Rudels et al. 2002; Håvik et al. 2017). Closer to the coast the mean velocities are smaller, with most stations being in the East Greenland Coastal Current (Bacon et al. 2002; Foukal et al. 2020; Håvik et al. 2017). Except for stations 5-7 on the 450-m isobath (i.e., immediate south of the Denmark Strait sill), the current is surface intensified and decreases monotonically with depth. South of the Denmark Strait sill, the deep flow (in the overflow plume) is stronger than the currents at middepth and at station 5 even than the near-surface currents; the deep flow backs with respect to the surface currents (i.e., is directed in a more southerly direction than the current near the surface), which is in line with observations (Harden et al. 2014a).

Figures $3 \mathrm{a}$ and $3 \mathrm{~b}$ show the vertical density structure for the stations on the 200- and 450-m isobath, respectively. All stations show stronger stratification near the surface. This is especially true in summer, when solar heating and melting ice add buoyancy to the surface layers. In winter, storms, brine rejection from freezing, and intense ocean heat loss erode the summertime stratification. The model is biased somewhat fresh in the upper ocean (Almansi et al. 2017; Saberi et al. 2020), and is therefore more stratified than observations (cf. the contours in Figs. $2 a$ and $2 b$ ). As will be shown in section $4 d$, differences in stratification have only a minor impact on the wave properties.

\section{Characteristics of subinertial variability in the numerical model}

Subinertial variability is manifested in variations about the mean conditions laid out in section 3 . This variability can be substantial: on the shelf, it can temporarily change the transport direction of the mean current (Foukal et al. 2020), which is important to keep in mind when working with synoptic surveys. We explore this variability with respect to mean conditions in sea surface height and current velocity.

\section{a. Subinertial variability in sea surface height}

Model sea surface height time series are extracted at the 22 coastal and shelf break stations. The time series are detrended and have their time means subtracted, and a multitaper is applied to reduce broadband bias and spectral variance (Thomson 1982; Lilly 2019). The resulting spectral estimates are plotted in Fig. 4a. For reference the spectral estimates from the Ammassalik and the Qaqortoq tide gauges from hourly 

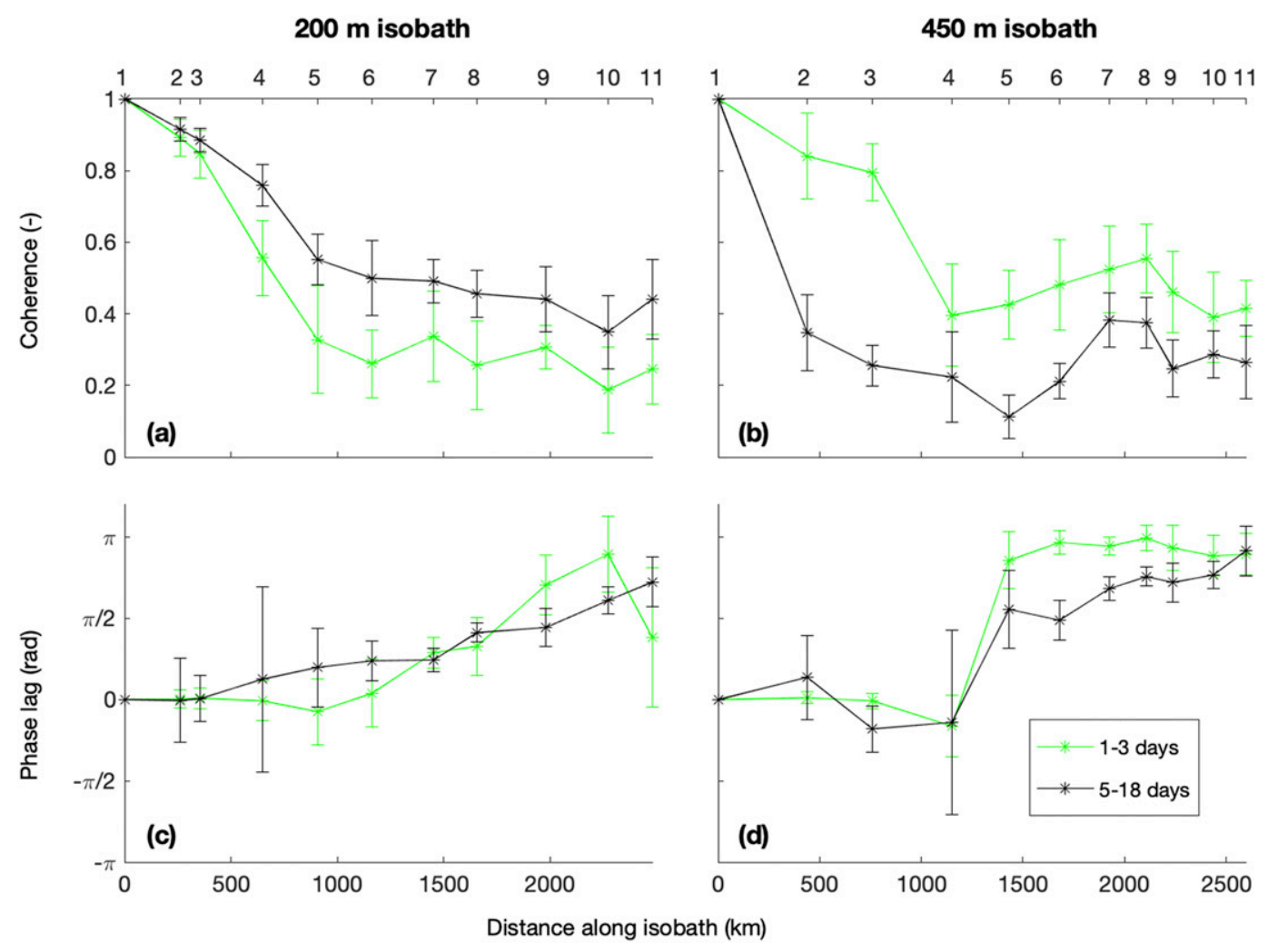

FIG. 5. Coherence $\gamma$ [Eq. (1)] (a),(b) magnitude and (c),(d) phase lag between the SSH anomaly time series at station 1 and the other stations along the (left) 200- and (right) 450-m isobaths (station positions are indicated along the top axes). The error bars in (a) and (b) are the standard deviation calculated on the basis of the frequency range; the error bars in (c) and (d) indicate the circular standard deviation calculated over the same frequency ranges (Grinsted et al. 2004). Color coding is as in Fig. 4.

data over 1994-95 are shown in Fig. 4b. The tide gauge records were first low-pass filtered using a tenth-order Butterworth filter with a cutoff frequency of 1.3 days and then subsequently were detided using T-TIDE (Pawlowicz et al. 2002) to remove any lower-frequency variability associated with tides.

Several maxima in the subinertial frequency range (left of the vertical gray dashed line) are found: first, two near-inertial peaks (0.5-0.6 and 0.6-0.7 days) are evident in all 200- and 450-m stations, indicating that there exists high-frequency variability with similar spectral behavior across the entire shelf in the model. These peaks lie between the diurnal and the semidiurnal tidal frequencies and are absent from the tide gauge records (even before low-pass filtering). We have carefully investigated this variability, and we conclude that they represent spurious variability in the form of a seiche about the GreenlandIceland-Scotland Ridge, probably arising as a resonance in response to discontinuities in the boundary forcing (which is piecewise linear in time after interpolation). To make sure the presence of this high-frequency variability has no major impact on our results, the low-pass-filtering procedure for the tide gauge record has also been applied to the model SSH time series in the remainder of the results shown.

Second, there is a broad spectral peak at almost all stations around 1.3-2.8 days (hereinafter referred to as 1-3 days), with a single outlier at station 5 along the 450-m isobath (just downstream of the Denmark Strait sill), which has its peak at slightly higher frequency (1.0-2.2 days), with much larger spectral power. The tide gauge records show elevated energy levels between 1 and 3 days as well, though perhaps split in two peaks (1-2 and 2-4 days). The Qaqortoq station in particular exhibits a sharp peak in the 1-2-day range. Third, there is a less distinct broad maximum around 10 days found at all model stations. The tide gauge record at Ammassalik shows several peaks in this frequency range including a relatively narrow peak around 10 days; the Qaqortoq record exhibits a broad peak more like the model records.

The similarities between the various curves in Fig. 4a are a strong indication of coherent variability. This coherence is now quantified by calculating the complex coherence between two time series, $x$ and $y$, as

$$
\gamma=\frac{S_{x y}}{\sqrt{S_{x x} S_{y y}}},
$$

where $S_{x y}$ is the cross spectrum of $x$ and $y$, and $S_{x x}$ and $S_{y y}$ are the one-sided spectra of $x$ and $y$, respectively. The magnitude of the complex coherence is a value between 0 and 1 , where 0 means no correlation and 1 means the two time series are 


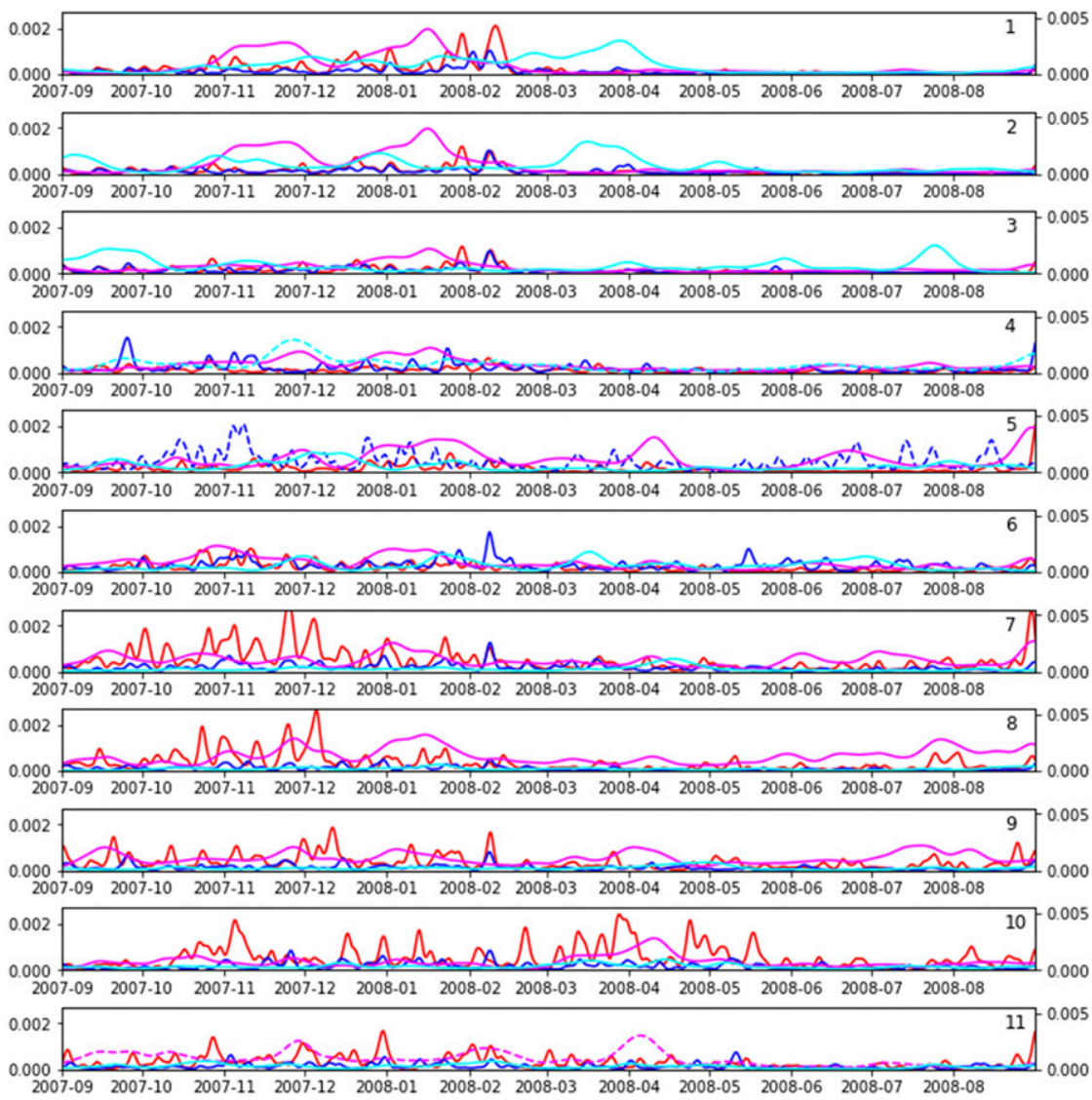

FIG. 6. Band-averaged wavelet energy time series for the 11 stations along the $200-\mathrm{m}$ isobath and 11 stations along the 450-m isobath in Fig. 1 (station numbers are in the top-right corner of each panel). Red: $200-\mathrm{m}$ isobath stations, 1-3 days; blue: $450-\mathrm{m}$ isobath stations, $1-3$ days; magenta: $200-\mathrm{m}$ isobath stations, 5-18 days; cyan: 450-m isobath stations, 5-18 days. The dashed curves are scaled for visualization purposes (they would not fit on the graph otherwise). For the full signal use the following multiplication factors: blue curve at station 5 : $\times 3$; cyan curve at station 4 and magenta curve at station 11: $\times 2$.

perfectly coherent at that frequency. The phase angle of the complex coherence is a measure of the phase lag between the time series, which may include multiples of $2 \pi$. We calculated the coherence for all station pairs on the $200-\mathrm{m}$ isobath and all pairs on the 450-m isobath and averaged the coherence magnitude and phase over the two frequency ranges identified from Fig. 4; the mean phase was calculated as the circular mean according to Grinsted et al. (2004).

The results for the coherence with station 1 on both isobaths is shown in Fig. 5. The coherence at $0 \mathrm{~km}$ is naturally 1 at 0 phase lag (the coherence of the time series with itself). The coherence (Figs. 5a,b) drops with distance along the coastline. Along the 200-m isobath (Fig. 5a), coherence in the 1-3-day signal drops faster than in the 5-18-day signal; the reverse is true for the 450-m isobath (Fig. 5b), where coherence between stations is stronger in the 1-3-day band. The same holds when coherence with a different station than station 1 is plotted (not shown). The phase lags (Figs. 5c,d) show different behavior too between the two isobaths: along the 200-m isobath (Fig. 5c), the phase gradually changes from 0 to $\pi / 2$ along the length of the shelf. The change is more gradual for the 5-18-day curve than for the 1-3 curve, which would be consistent with a longerwavelength propagating signal in the 5-18-day band than in the 1-3-day band. Along the 450-m isobath (Fig. 5d), the phase difference is small up to station 4 and then suddenly shifts across the Denmark Strait sill. This is particularly evident in the 1-3-day curve, as the 5-18 curve exhibits a large uncertainty at station 4 .

Another way to visualize coherence along and across the continental shelf is with a wavelet analysis (Torrence and Compo 1998). We calculate the energy contained in the two frequency bands above using a continuous Morlet wavelet transform $\left(\Psi_{0}(\eta)=\pi^{-1 / 4} e^{i \omega_{0} \eta} e^{-\eta^{2} / 2}\right)$ with nondimensional frequency $\omega_{0}=6$, which is a common choice for feature extraction as it provides a good balance between time and frequency localization (Grinsted et al. 2004); $\eta$ is the dimensionless time. This procedure yields a time series of wavelet energy per frequency band for every station analyzed. The results (Fig. 6) show pulses of energy (note that individual peaks in Fig. 6 are not waves, but an elevated level of energy in that frequency 

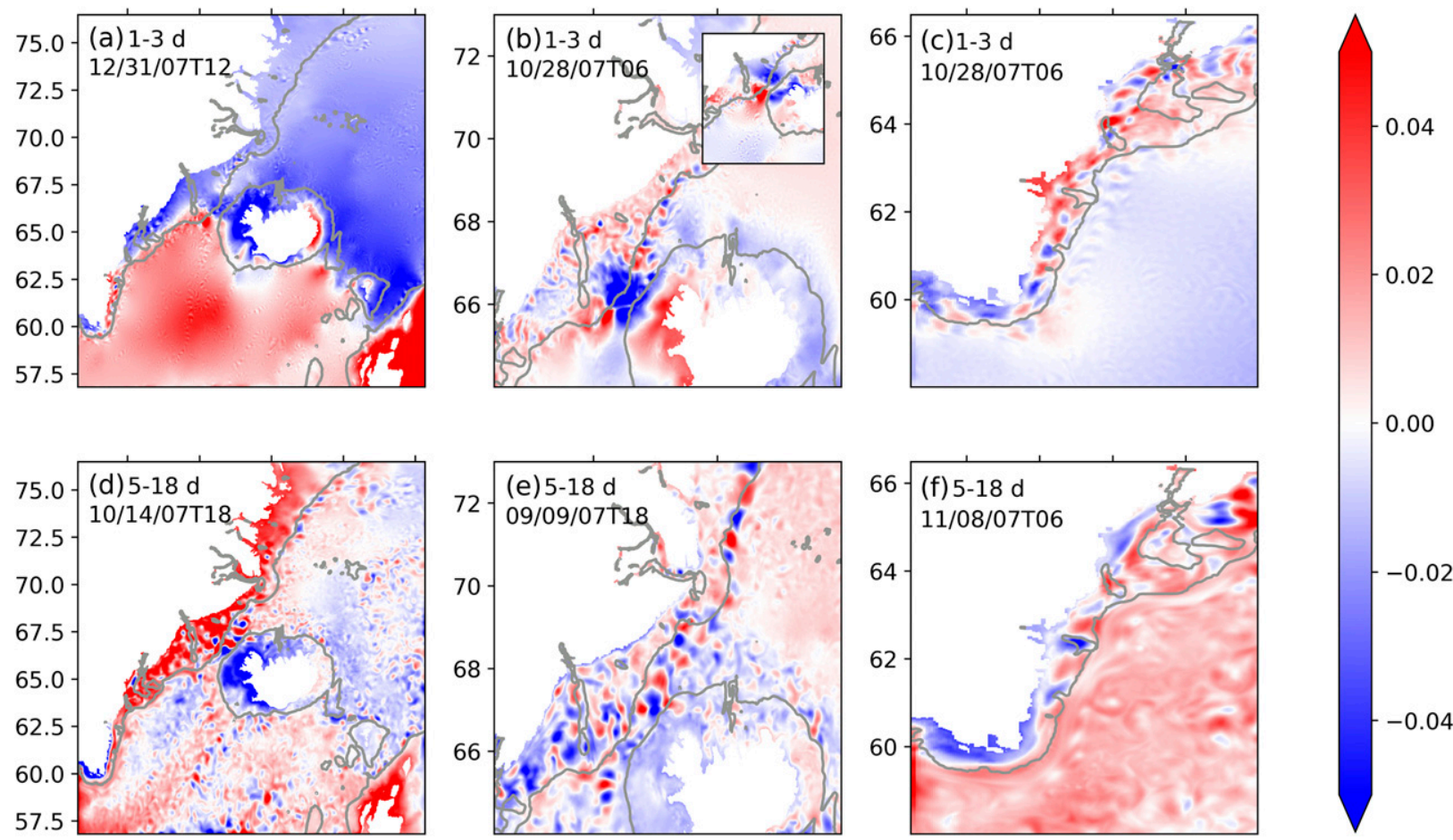

FIG. 7. Snapshots of bandpassed-filtered sea surface height anomalies. The snapshots are subjectively selected to highlight certain features for (top) 1-3 and (bottom) 5-18 days. (a) A shelf wave along the coast spanning the width of the continental shelf. There are also features propagating around Iceland and around Reykjanes Ridge. Another snapshot, zoomed in to different regions, shows that slow, short waves are found both (b) along the shelf break upstream of the Denmark Strait sill and (c) on the shelf along the coast starting at the entrance of Sermilik Deep. Two phases of the phase locking of counterpropagating waves in Denmark Strait (one travels south to north around Iceland and the other travels north to south on the Greenland side) are shown in (b) and its inset. The wavelength is roughly the length of the Denmark Strait, and the waves accelerate passing through the strait (see also Fig. 11a, below, and the animations in the online supplemental material to verify the phase locking). (d) The fast shelf wave—here occupying the entire length of the model shelf. (e),(f) The slower short waves along the shelf break in the same regions as (b) and (c), respectively.

band at that location), which in some cases persist over several stations. The blue peak in early February 2008, for example, can be traced all the way from station 1 to station 11 . The red peaks in the first half of the station 7 record, on the other hand, seem to start at station 6, grow in amplitude, and die out after station 9. Some events (especially for the 1-3-day curves around Denmark Strait) are even local to only one station.

Both analyses presented above show strong evidence for spatially coherent variability, but we can go a step further: one of the major advantages of analyzing model data is that the full 4D fields are available for analysis. We will now determine the spatial patterns that accompany the signals found above. To this end, the sea surface height anomaly time series of every grid point in the entire model domain is individually bandpass filtered for two pass bands based on the maxima identified in Fig. 4. We used a fifth-order Butterworth filter and passed the filter forwards and backward to avoid phase shifting of the signals. Animations of the time-evolving fields are provided as online supplemental material to this paper; Fig. 7 shows snapshots selected to highlight certain features.

Figures $7 \mathrm{a}-\mathrm{c}$ are examples of the 1-3-day bandpass-filtered fields. Figure 7a exhibits a traveling wave on the Greenland continental shelf, spanning the width of the shelf, and propagating with the coast on the right-hand side. This is characteristic for continental shelf waves (purely barotropic CTWs). A traveling wave around Iceland of a single wavelength is also evident in the 1-3-day (as well as the 5-18 day) bandpass-filtered fields, and less obvious but still present are waves along the Greenland-Iceland-Scotland Ridge and along Reykjanes Ridge (the red blob southwest of Iceland). The inset in Fig. $7 \mathrm{~b}$ and the figure itself show the merging of a wave traveling in northeasterly direction around Iceland (in clockwise direction, with the coast on the right-hand side) and a wave of similar wavelength traveling southwestward along the Greenland shelf, also with the coast on the right-hand side (note that these are snapshots from two different events, but they are representative for this phenomenon as can be seen in the animation). The two waves phase lock at the Denmark Strait sill and appear to energize the wave traveling along the Greenland coast, which is consistent with the much larger spectral peak at station 5 than at other stations (Fig. 4a). Figures $7 \mathrm{~b}$ and $7 \mathrm{c}$ both show traveling waves of a much shorter wavelength than the one in Fig. 7a, predominantly along the shelf break upstream of the Denmark Strait sill (Fig. 7b) and predominantly on the shelf along the coastline starting at Sermilik Deep (Fig. 7c). The latter pathway has been 

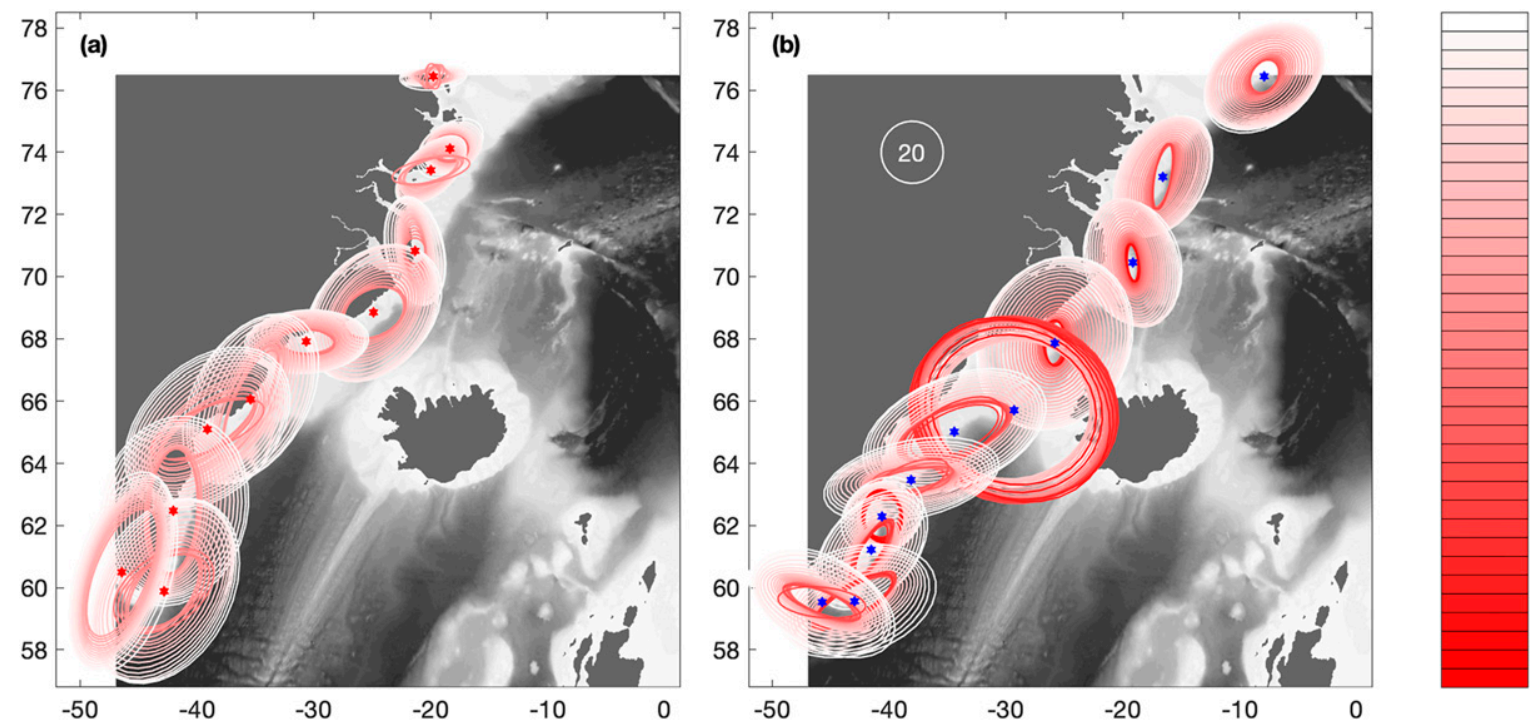

FIG. 8. Variance ellipses of velocity fluctuations at the (a) 200- and (b) 450-m isobath stations, color-coded by depth (m). The white circle in (b) is for scale, with a diameter of $20 \mathrm{~cm} \mathrm{~s}^{-1}$.

documented from mooring observations by Harden et al. (2014b). Figures 7d-f are examples of the 5-18-day bandpassfiltered fields, which show similar features as the 1-3-day filtered fields but with larger wavelengths: this frequency band also exhibits a fast-traveling wave along the continental shelf (Fig. 7d), which in this case spans almost the entire length of the shelf in the model domain for half a wavelength. Figures $7 \mathrm{e}$ and $7 \mathrm{f}$ show the shorter-wavelength, slower-moving wave on the shelf break, with a larger wavelength than in the 1-3-day frequency band.

In summary, spectral peaks in the SSH anomaly time series are found around 1-3 days and a broad peak around 10 days. The signals show strong coherence along and across the shelf. There are two types of spatial patterns in the bandpass-filtered fields associated with these frequency bands. First, a fastmoving wave spanning the width of the continental shelf that travels with the coast on the right-hand side. This type of wave is present in both frequency bands and has a larger wavelength in the lower-frequency range. Second, slow-moving shortwavelength waves are found along the shelf break and on the shelf near the coastline. These waves are also longer in the 518-day band than in the 1-3-day band. Upstream of and in the Denmark Strait, these waves are most prominent along the shelf break; from Sermilik Deep onward the coastal wave has a larger amplitude.

\section{b. Subinertial variability in velocity fluctuations}

Current velocity can also shed light on subinertial variability. Unlike SSH, current fluctuations contain information on vertical structure of the variability. Furthermore, if the subinertial variability is a signature of waves, we expect to find a consistent relationship between the $\mathrm{SSH}$ anomalies and the current fluctuations in the frequency range in question (see section $4 c$ ). In this section we focus on the velocity fluctuations.
Velocity variance ellipses indicate the magnitude and preferred direction of current variations with respect to the mean flow. Figure 8 shows the variance ellipses of the velocity fluctuations at the 22 coastal and shelf break stations. The ellipses are drawn for all model depth levels in the water column; color coding is by depth, with light colors near the surface. The ellipses portray behavior that is characteristic for boundary current variability: the ellipses are more elongated and aligned with the bathymetry at depth compared to the surface, as the solid boundaries constrain lateral current fluctuations. The magnitude of the fluctuations also decreases with depth as bottom friction becomes more important. Although the stations share many similarities, the shelf stations downstream of Denmark Strait have larger current fluctuations than the shelf stations upstream of Denmark Strait (Fig. 8a). This is consistent with the observation in section $4 \mathrm{a}$ that the shortwavelength traveling waves are more prominent on the shelf in the Irminger Sea. The shelfbreak station directly downstream of the Denmark Strait sill (station 5) portrays different behavior from other stations: the ellipses are near circular and increase rather than decrease in size with depth. The velocity fluctuations at this station are thus dominated by bottom-intensified eddies, as expected for a station in the path of the DSO eddies.

The variance ellipses indicate that the preferred direction of the current variability is alongshore. They do not give information on the frequency ranges that variability is manifested in (the current ellipses of bandpass-filtered velocity time series are only qualitatively different at station 5 on the $450-\mathrm{m}$ isobath for the 5-18-day frequency range, where the DSO eddy signal is no longer evident). We thus calculate the rotary spectra of the current fluctuations. For example, Fig. 9 shows the cyclonic and anticyclonic spectra at 100-m depth of station 4 along the 200- and 450-m isobaths. Inertial oscillations on the shelf are clear in Fig. 9 as there is a broad peak around the inertial frequency in the anticyclonic side of the spectrum 


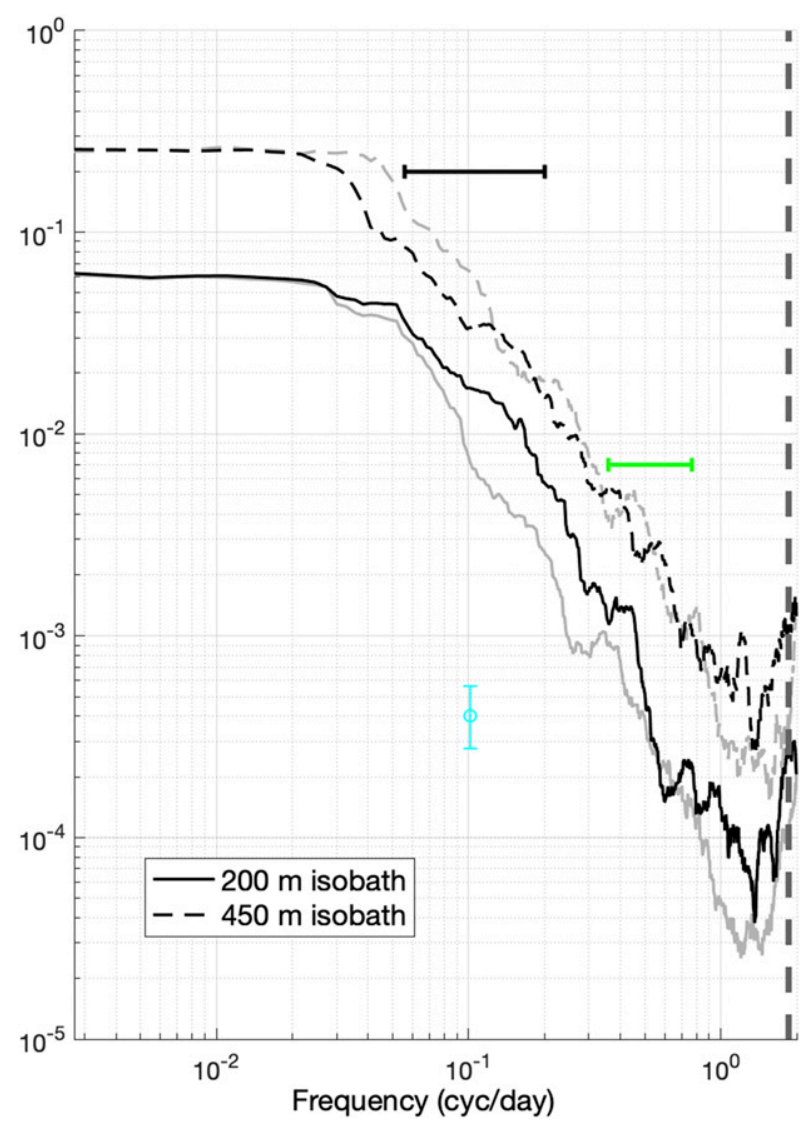

FIG. 9. Rotary spectra of the velocity fluctuations at 100-m depth at station 4 along the 200-m isobath (solid) and station 4 along the 450-m isobath (dashed). Gray curves: cyclonic; black curves: anticyclonic. The color-coded whiskers are the frequency ranges from Fig. 4. The vertical dashed gray line is the inertial frequency at $68^{\circ} \mathrm{N}$.

(solid black curve) only, which is consistent with inertial oscillations in the Northern Hemisphere. Inertial oscillations are evident in stations $2-6$ on the $200-\mathrm{m}$ isobath (not shown), but none of the $450-\mathrm{m}$ isobath stations exhibit this feature. In general, the $200-\mathrm{m}$ isobath station spectra are more consistent with each other than the 450-m isobath station spectra.

The peaks in the SSH spectra are indicated in Fig. 9 using whiskers with the same colors as Fig. 4. In the 1-3-day range, there are 1 or sometimes 2 peaks in the velocity spectra. On the 200-m isobath, the energy in the anticyclonic component consistently exceeds the energy in the cyclonic component, though maxima are evident in both spectra. On the 450-m isobath, the 1-3-day peaks are present in the stations upstream of the Denmark Strait and downstream of it the peak has shifted to 24 days (not shown). The 5-18-day peak is visible as a weak and broad maximum at most stations. At the $450-\mathrm{m}$ isobath stations, the peak is somewhat narrower than in the SSH anomaly spectra and confined to roughly 5-12 days.

\section{c. Wave properties}

The evidence in section 4 a shows that waves exist in the sea surface height field in the subinertial frequency range, propagating with the coast on the right-hand side. This is physically consistent with CTWs in the Northern Hemisphere. In this section we analyze the properties of the waves found in the model fields.

Figures 10 and 11 show Hovmöller diagrams of the SSH signals on the 200- and 450-m isobaths, respectively, bandpass filtered over 1-3 (Figs. 10a, 11a) and 5-18 days (Figs. 10b, 11b). A limited time frame is displayed to highlight the propagating signals. Figure 10 is dominated by near-horizontal stripes: these are barotropic waves that propagate at a speed of hundreds of kilometers per day. The entire length of the shelf (about $2000 \mathrm{~km}$ ) fits two waves in the 1-3-day band and half a wave in the 5-18-day band, which gives wavelengths of 1000 and $4000 \mathrm{~km}$, respectively. Slower-propagating signals are present too, for example starting at the entrance of Sermilik Deep (at a distance of $2500 \mathrm{~km}$ in Fig. 10). Recall from Fig. 7 that the slower waves upstream mostly manifest along the shelf break (see also Fig. 11). The phase speed of the short waves on the shelf as derived from the slope of the lime-green lines is roughly $0.5 \mathrm{~m} \mathrm{~s}^{-1}$ in the 1-3-day band and slightly faster in the 5-18-day band-2 times as fast as the mean flow. Along the shelf break (Fig. 11) short waves with a wavelength of $40 \mathrm{~km}$ propagate in the 1-3-day band with a phase speed of $0.38 \mathrm{~m} \mathrm{~s}^{-1}$ in the Blosseville Basin (directly upstream of station 4). Along the same stretch in the 5-18-day fields the waves are $200 \mathrm{~km}$ long and the phase speed is $0.19 \mathrm{~m} \mathrm{~s}^{-1}$. Still, these waves move faster than the mean flow by factors of 4 and 2, respectively. At the Denmark Strait sill (between stations 4 and 5) the two frequency bands behave differently. The waves in the 5-18-day band continue as before, but the waves in the 1-3-day band accelerate over the sill with a mean speed of $2.72 \mathrm{~m} \mathrm{~s}^{-1}$ and grow in amplitude. Downstream of the sill, the phase speeds of the waves in the two frequency bands are the same at $0.44 \mathrm{~m} \mathrm{~s}^{-1}$, which is slightly higher than the upstream value in the 1-3-day band and much faster than in the 5-18-day band. It is surprising that we find the same phase speeds in these two frequency bands because the properties differ elsewhere along the shelf. The wavelength in the 1-3- and 5-18-day bands is 80 and $200 \mathrm{~km}$, respectively. The waves are particularly evident where the shelf is narrow (in the Irminger Sea). These are the same waves as the ones in Fig. 10a because the 200- and 450-m isobaths are close together at this stretch of coastline (see Fig. $7 \mathrm{~d}$ and also the animations in the online supplemental material).

\section{d. Comparison with theory}

We compare the model waves with CTW solutions from theory in this section. The theoretical solutions cannot fully account for both strong alongshore mean flow (e.g., Niiler and Mysak 1971; Mysak 1980) and strong alongshore and crossshore changes in bathymetry (e.g., Johnson and Clarke 2001; Rodney and Johnson 2012, 2014, 2015). We therefore choose a model section that is upstream of the largest bathymetric changes (cyan line in Fig. 1), where the theory is least erroneous. We compute CTW solution modes using the iterative method of Brink (1982, 2006), which accounts for a (steady, surface intensified) mean flow. Details of the procedure can be found in the manual (Brink 2018); in essence, the algorithm 


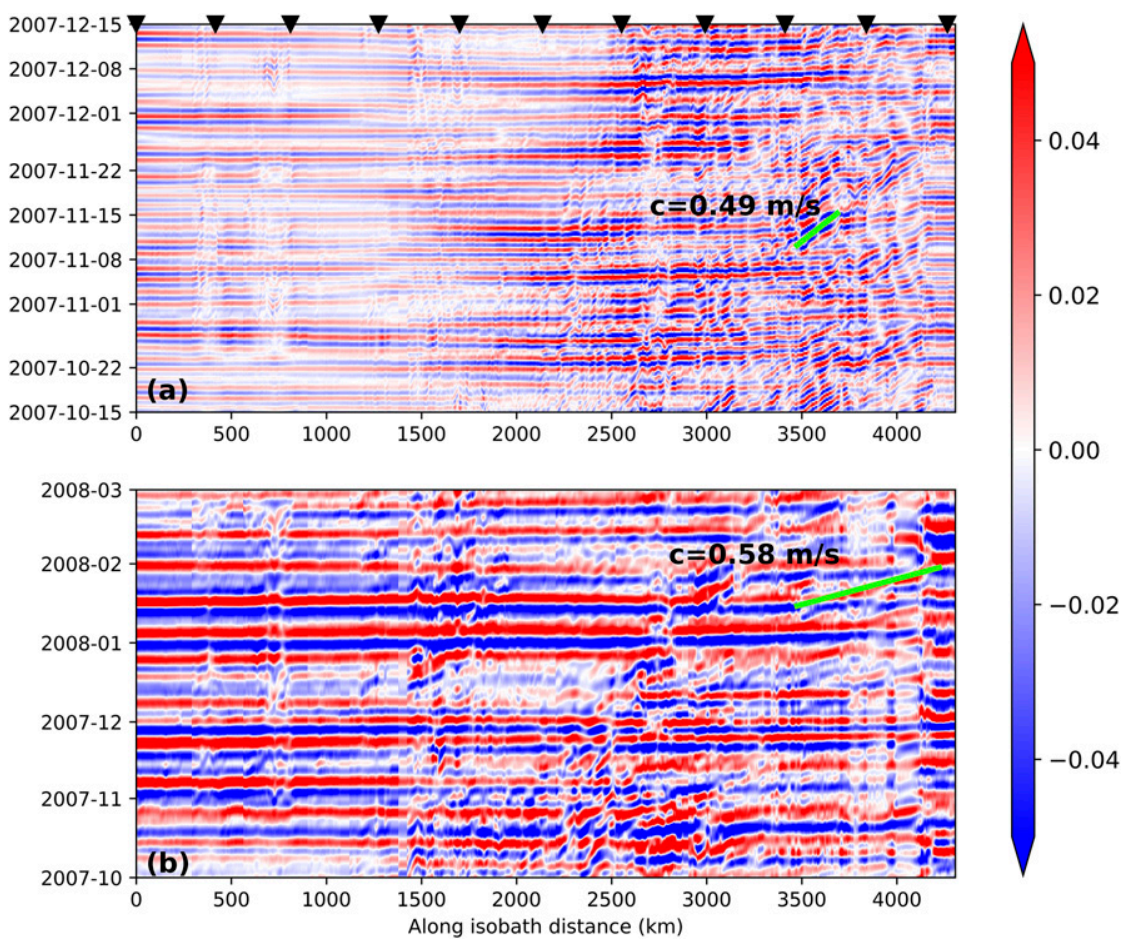

FIG. 10. Hovmöller diagrams of bandpass-filtered SSH anomaly signals along the 200-m isobath (green curve in Fig. 1): (a) 1-3-day pass band and (b) 5-18-day pass band. The alongisobath locations of the 11 stations are indicated by the black downward-facing triagles. The $y$ axes are time [tick marks in (b) are on the first of the month]. Green slanted lines indicate inferred phase speeds.

solves a partial differential equation for the pressure field iteratively to find a valid combination of pressure, wave frequency, and alongshore wavenumber, given a bathymetric profile, a density field, Coriolis frequency, mean flow structure and speed, top and bottom boundary conditions for surface and bottom stress, and open or closed side boundary conditions. The bathymetry on our section is approximated [following Dale et al. (2001) and Inall et al. (2015)] by a flat 80-km-wide and 300-m-deep shelf, a 40-km-wide continental slope, and a flat $80-\mathrm{km}$-wide ocean floor at $1650-\mathrm{m}$ depth, which represents the cross-shelf profile well (Fig. 12b). At the offshore edge of the domain an open boundary condition is applied. For the stratification, the mean summer and winter profiles from Fig. 3 are used. The Brink $(1982,2006)$ method is known to fail to find solutions when the spatial scale of the wave is much smaller than the domain width. Indeed, we cannot find stable solutions for very short waves or modes higher than II.

The dispersion relations for the first two CTW modes are plotted in Fig. 12a. We consider several cases for summer and winter stratification and surface-intensified mean flows between 0.1 and $0.4 \mathrm{~m} \mathrm{~s}^{-1}$. In all cases the stratification differences are unimportant. The solutions are sensitive to the mean flow for wavelengths less than about $300 \mathrm{~km}$. In these cases, stronger mean flow increases the wave frequency and thus the phase speed at fixed wavenumber. The effect is most pronounced in the mode-I solutions. Variations in the strength of the mean flow have little impact on the cross-shore spatial structure of the wave solutions. The bathymetry has a significant impact on the wave solutions, but a detailed exploration of its effect is unnecessary for the goals of this paper.

The three wave solutions diagnosed from the model fields that fall within the $\omega-k$ range of Fig. 12a are indicated by the connected open circles. The long fast waves on the shelf (both 1-3 and 5-18 days) are in the lower left corner and are consistent with the mode-I theory. The shorter 5-18-day waves at the shelf break fall at lower frequencies than the mode-II theoretical curve. On the basis of their low phase speed and (cross shelf) spatial structure, we hypothesize that these waves are mode-III waves, which the Brink (2006) algorithm fails to identify. A hypothetical mode-III curve is added to the dispersion diagram as a gray dashed line, based on expectations from the literature (e.g., Caldwell et al. 1972). The presence of a mode-III wave on the shelf break is supported by evidence from Pacini et al. (2020), who found this mode at the shelf break in southwest Greenland.

To compare the cross-shore spatial structure of the model waves with the CTW theory we perform a multivariate empirical orthogonal function (MEOF) analysis on the model $\mathrm{SSH}$ and surface velocity fields along the same cyan line in Fig. 1 that was used to find the theoretical solutions (we performed the analysis also with bandpass-filtered fields, which yielded very similar results). The purpose of this MEOF analysis is to find coupled variability structures between the different (model) variables that are associated with CTWs, so 


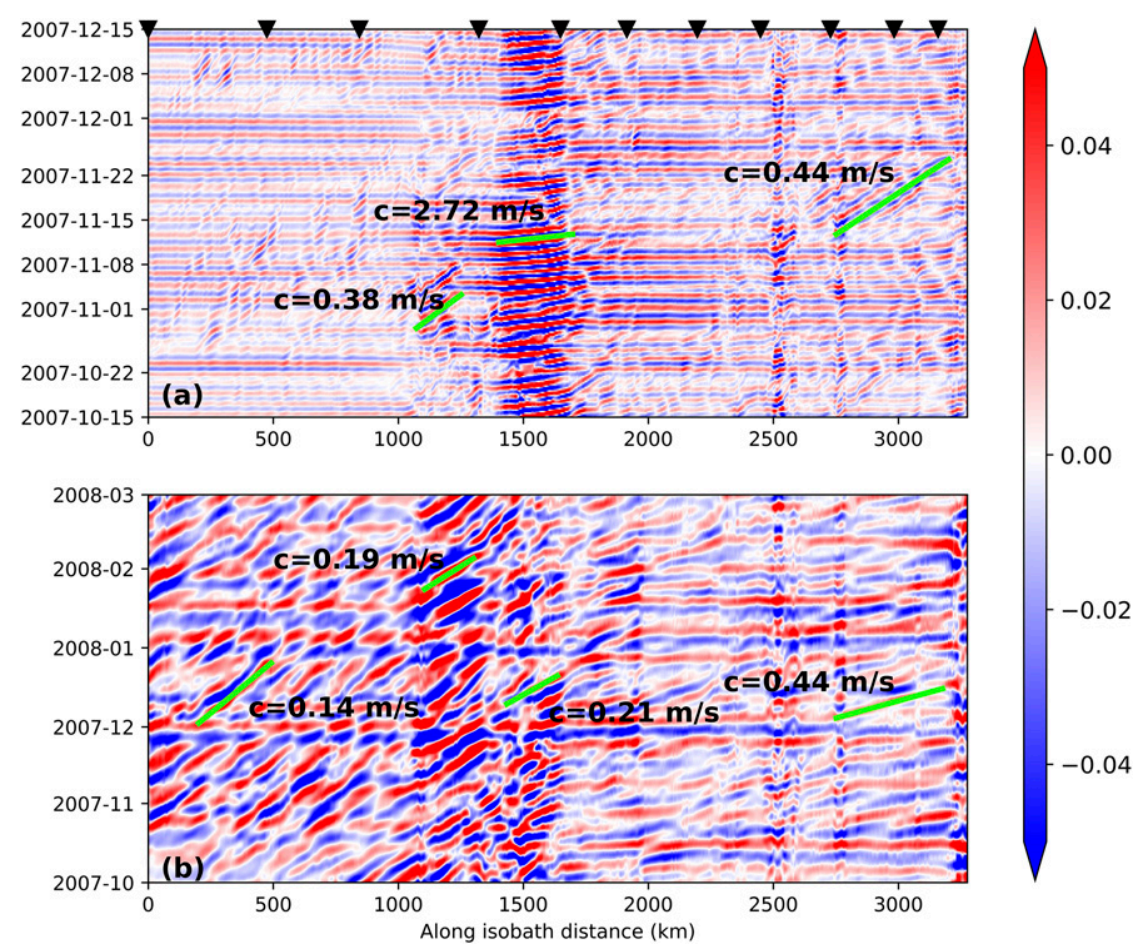

FIG. 11. As in Fig. 10, but for the 450-m isobath (magenta curve in Fig. 1).

that they can be directly compared with the theoretical solutions. Before calculating the MEOFs, we remove the time mean from each model field and normalize them with their global standard deviation. This ensures equal contribution of all fields to the MEOF variance analysis (Wheeler and Hendon 2004). All MEOFs presented here are independent based on North's criterion (North et al. 1982). MEOFs I and II have no zero crossing in SSH and therefore do not resemble CTWs. Figures 12c-e show MEOFs III-V, which explain 14\%, 9\%, and $6 \%$ of the total combined variance, respectively.

In Fig. 12a, four examples of theoretical CTW wave structures are plotted (insets A-D), to be compared with the MEOF structures. In general, variance is maximized closer to the coastline for low wavenumbers (A and B), and in the shelf break region for higher wavenumbers (C and D). At low wavenumbers, the along-shelf velocity (red curve) is at a uniform maximum across the shelf; at higher wavenumbers the maximum is instead midshelf with a slight reduction in amplitude toward the coast. The pressure (blue curves) is maximum at the coast in the mode I cases (A and C), while it is zero at the coast for mode II (B and D). Cross-shore velocity (green curves), finally, is zero at the coast for both mode I and mode II waves, increases in magnitude to a maximum midshelf, and then decreases. Although the model MEOF structures are noisy, especially close to the coast where the model fields are impacted by more complicated bathymetry (Fig. 12b), they are remarkably similar to the CTW modes in Fig. 12a. In particular, MEOF III (Fig. 12c) has a maximum SSH at the coast and a midshelf maximum for along-shelf velocity. This would be consistent with a mode I wave of moderate to high wavenumber. MEOF IV (Fig. 12d) has zero SSH anomaly at the coast and a broad maximum along-shelf velocity (only going to zero very close to the coast). This is consistent with the structures found in mode II waves in Fig. 12a. MEOF V (Fig. 12e) is inconclusive as it shows features of both mode I and mode II waves, but is also a lot more noisy (particularly in alongshore velocity) than MOEFs III and IV. Overall, the variability in the 1-3-day and 5-18-day bands in the MITgcm model solution are consistent with CTWs.

\section{The role of wind in driving subinertial variability}

We have shown the presence of subinertial variability in several of the model fields, the frequency bands in which they are manifested, their spatial structures, and that the model variability in these frequency bands exhibit behavior that is consistent with the known properties of CTWs. This naturally leads to the question what drives this variability. One of the driving forces often suggested in the literature is wind-in particular strong alongshore winds (e.g., Harden et al. 2014b; Inall et al. 2015). To investigate the possible role of wind, we perform an MEOF analysis on the combinations of ASRv2 wind speed fields and bandpass-filtered SSH anomaly fields.

Figure 13 shows an example of the results from the MEOF analyses (chosen because it highlights the signature of shelf waves). Figures $13 \mathrm{a}$ and $13 \mathrm{~b}$ show the second EOFs for $\mathrm{SSH}$ anomaly and wind speed, respectively. This EOF explains $9 \%$ of the total variance in the two combined fields; the first EOF (not shown) is mostly a signature of the seasonal cycle in wind speed and contains $14 \%$ of the total variance. The most striking 

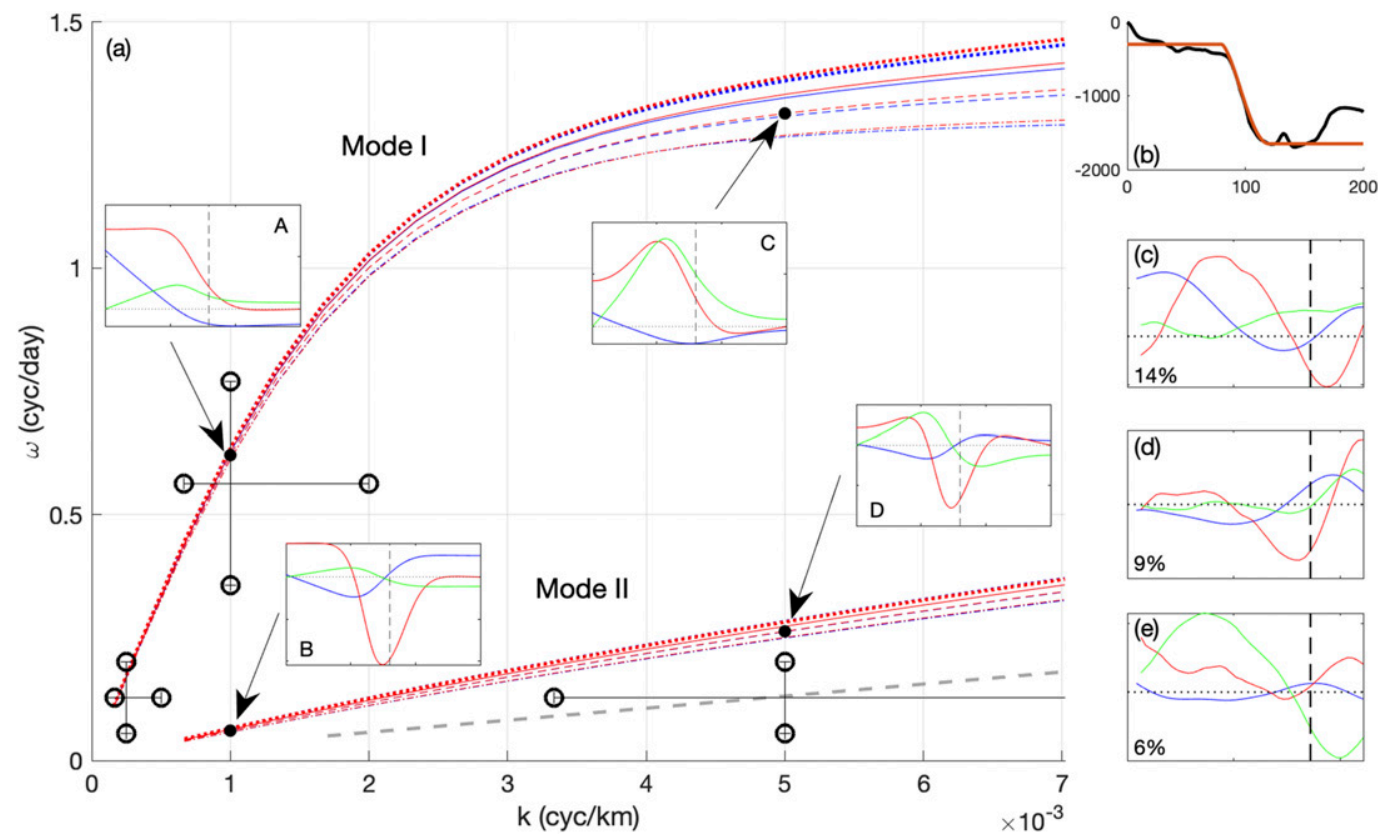

FIG. 12. (a) Dispersion diagram for waves at cyan shelf section in Fig. 1. Red curves are for summer stratification, and blue curves are for winter. The line styles indicate the strength of the background flow with a maximum southward surface speed of 0.1 (dash-dotted), 0.2 (dashed), 0.3 (solid), and 0.4 (dotted) $\mathrm{m} \mathrm{s}^{-1}$. The gray dashed curve is a hypothetical mode-III curve (see the text for details). The connected open circles indicate $\omega-k$ combinations of waves diagnosed from the model fields (the frequency range is based on the pass band applied in the filter; the wavenumber uncertainty range indicated represents 0.5 wavelength). The insets (labeled A-D) are examples of surface structures from the Brink $(1982,2006)$ model solution found for the four points indicated in the diagram by solid circles. In the insets as well as in (c)-(e), blue is pressure, red is alongshore velocity in the direction of wave propagation, and green is cross-shore velocity away from the coast. The dashed vertical line is the position of the shelf break; the horizontal dotted line is the zero position on the $y$ axis. (b) Section bathymetry in the numerical model (black) and idealized approximation (brown). Also shown are EOF modes from an MEOF analysis on SSH anomaly and alongshore and cross-shore velocity along the cyan section in Fig. 1: (c) mode III explains $14 \%$ of the total variance, (d) mode IV explains $9 \%$ of the total variance, and (e) mode V explains $6 \%$ of the total variance.

feature in Fig. 13a is the elevated positive (note that the sign is arbitrary) band along the Greenland shelf, combined with peaks and troughs spanning the width of the shelf within this band of high positive values. This physically corresponds to a continental shelf wave (spanning the entire length of the shelf at this frequency, Fig. 7d) with shorter waves superimposed. The corresponding wind EOF resembles a barrier wind (Petersen et al. 2009). (Figure 13c shows that the barrier wind pattern found in the MEOF analysis is very similar to the third EOF of wind speed only, explaining $7 \%$ of the variance in the fields of this variable.) The amplitude of the second (shared) principal component that accompanies both MEOF fields in Figs. $13 \mathrm{a}$ and $13 \mathrm{~b}$ is shown as the blue curve in Fig. $13 \mathrm{~d}$. Consecutive sharp maxima correspond to peaks and troughs in the phase of a continental shelf wave in this frequency band, as illustrated in Figs. 13e-h. The green curve in Fig. 13d illustrates a partial correspondence between local elevated levels of wavelet energy and periods of large-amplitude peaks in the second principal component.

The evidence in Fig. 13 is inconclusive but indicates that at least part of the variability in the 5-18-day frequency band is forced by barrier winds. Performing the same analysis on the 1-3-day bandpass-filtered fields shows that variability in this frequency band is also partially wind driven. In this case the wind speed maximum is further south over Sermilik Deep (see also Harden et al. 2014b). This pattern corresponds to the second EOF of wind speed alone. So, the second and third wind speed EOFs (not MEOFs) are associated with SSH variability in the 1-3-day and the 5-18-day frequency bands, respectively. Not all variability in these frequency bands is linked to wind forcing, however.

\section{Summary and discussion}

The goals of this study are to show that (i) subinertial variability along the southeast Greenland coast is coherent along and across the continental shelf, and (ii) the frequency bands of this variability and their spatial structures are consistent with CTWs. We use output from a realistic high-resolution numerical simulation to diagnose and characterize subinertial variability in the flow field with a focus on SSH anomalies and velocity fluctuations.

We find two subinertial bands in the frequency spectrum of SSH anomaly time series, at $1-3$ and at 5-18 days. Using 

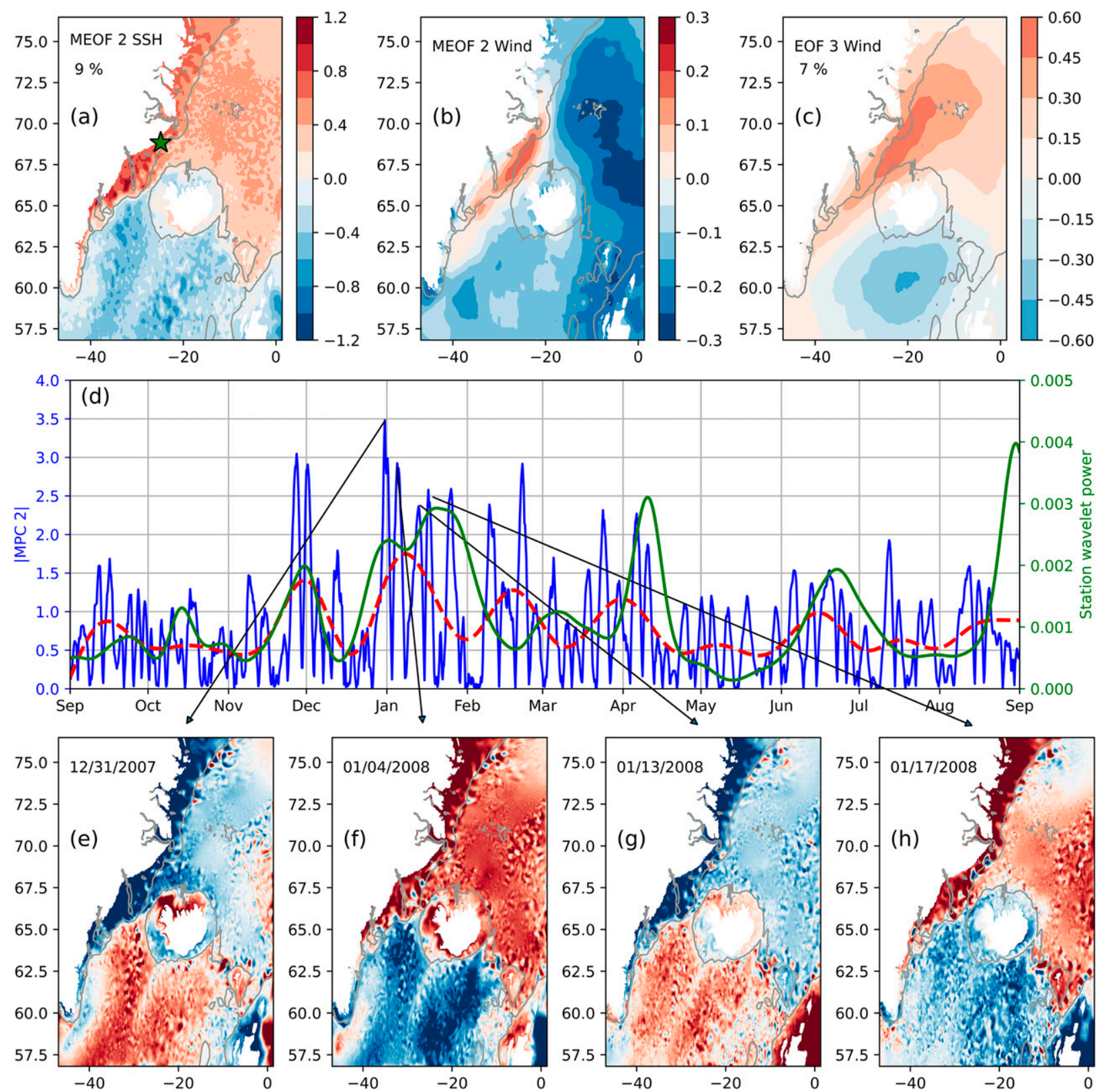

FIG. 13. Example of results of multivariate EOF analysis. The MEOF is performed on the 5-18-day bandpass-filtered SSH anomaly and wind speed fields. (a) Second EOF for SSH from MEOF; (b) second EOF for wind speed from MEOF; (c) third EOF from regular EOF analysis based on wind speed only. (d) Blue: absolute value of the second principal component from the MEOF; red dashed: 5-day lowpass-filtered version of the blue curve; green: 5-18-day band-averaged wavelet energy (see Fig. 6) at the fifth station along the 200-m isobath [green star in (a)]. (e)-(h) Snapshots of the 5-18-day bandpass-filtered SSH anomaly fields at times of maximum amplitude of the shelf wave. Times are indicated in the top left of the panels and are linked to (d) with gray arrows. Gray contours in (a)-(c) and (e)-(h) are the 450-m isobath.

statistical coherence and visual inspection of the time-varying $\mathrm{SSH}$ fields, we show that much of this variability is spatially coherent. In particular, we find two types of waves: (i) longwavelength $(1000-4000 \mathrm{~km})$ fast-propagating (hundreds to thousands of kilometers per day) waves on the continental shelf that span the width of the shelf, and (ii) short-wavelength (from tens to hundreds of kilometers) slowly propagating
(0.1-0.5 $\mathrm{m} \mathrm{s}^{-1}$ ) waves along the shelf break upstream of Sermilik Deep and along the coast downstream of Sermilik Deep.

CTW properties from theory are consistent with the subinertial variability in the model. The fast, long waves in the 1-3and 5-18-day bands are consistent with a mode-I wave. The short waves along the shelf break in the 5-18-day band are likely mode-III waves. We are unable to ascertain that the 
shelf-break wave in the 1-3-day range is a CTW, but the structure (Figs. 7b,c) and propagation (Fig. 11a) are consistent with CTWs. The 5-18-day fast shelf waves are sometimes associated with barrier wind events, whereas the 1-3-day waves are sometimes associated with strong northeasterly winds over Sermilik Deep.

The variability around the Denmark Strait sill differs from the variability elsewhere. In the 1-3-day band in particular, the waves accelerate and grow in amplitude as they approach the sill, morph temporarily into coherent eddies, and return to wavelike characteristics downstream of the Denmark Strait sill. Boluses and pulses at the Denmark Strait sill are possibly associated with this steepening, as the extreme phase speed acceleration promotes nonlinearities. The phase-locking behavior at the Denmark Strait sill of waves traveling southward along the Greenland coast with waves propagating northward around Iceland (Fig. 7b) is reminiscent of the flooding events described by Spall et al. (2019) in the way the flooding events are associated with an intense meandering of the hydrographic front. The phase-locking phenomenon provides a way to energize and possibly destabilize the frontal currents. The phaselocking occurrence frequency is, however, much higher than once a month; it is possible that the flooding event is one possible manifestation of this phase-locking phenomenon.

While this study has shown that CTWs are indeed a prominent feature of the ocean dynamics along the southeast Greenland coast, many open questions remain. For example, wave motion around Iceland appears to be intricately linked to wave motion along the southeast Greenland coast, and the two together appear to determine wave propagation in the Denmark Strait. Wave dynamics around Iceland are particularly interesting as the allowable wavelengths are set by the circumference of the island. Characterizing and understanding wave dynamics around Iceland is thus crucial to understanding subinertial variability in the Denmark Strait, and this will be discussed in a follow-up paper. A second largely open question is what drives the subinertial variability, and in particular whether the waves are forced locally or remotely. We have shown that local wind events can account for some of the variability, but not all of it, indicating at least some waves are likely forced remotely and brought in through the open boundaries. This question is left for a future paper. A third area that is largely unexplored in this paper is the impact of along-shelf variations in bathymetry on wave properties. Emergent theoretical work on this topic (e.g., Rodney and Johnson 2014) shows a rich behavior, and promises a future better understanding of the nonlinear dynamics in our numerical simulation.

Acknowledgments. This work was supported by the National Science Foundation under Grant OCE-1756863. The authors are grateful for a constructive discussion on data analysis with Jonathan Lilly.

Data availability statement. The numerical model solution is publicly available on SciServer (http://sciserver.org), which is developed and administered by the Institute for Data Intensive Engineering and Science at The Johns Hopkins University.
Instructions for accessing the dataset are available at this site (https:/oceanspy.readthedocs.io). The tide gauge data are available at http://uhslc.soest.hawaii.edu/network/. The Kögur array data are available at http://kogur.whoi.edu/php/index.php.

\section{REFERENCES}

Adams, J. K., and V. T. Buchwald, 1969: The generation of continental shelf waves. J. Fluid Mech., 35, 815-826, https://doi.org/ 10.1017/S0022112069001455.

Almansi, M., T. W. N. Haine, R. S. Pickart, M. G. Magaldi, R. Gelderloos, and D. Mastropole, 2017: High-frequency variability in the circulation and hydrography of the Denmark Strait Overflow from a high-resolution numerical model. J. Phys. Oceanogr., 47, 2999-3013, https://doi.org/10.1175/ JPO-D-17-0129.1.

—, R. Gelderloos, T. Haine, A. Saberi, and A. Siddiqui, 2019: OceanSpy: A Python package to facilitate ocean model data analysis and visualization. J. Open Source Softw., 4, 1506, https://doi.org/10.21105/joss.01506.

- T. W. N. Haine, R. Gelderloos, and R. S. Pickart, 2020: Evolution of Denmark Strait overflow cyclones and their relationship to overflow surges. Geophys. Res. Lett., 47, e2019GL086759, https://doi.org/10.1029/2019GL086759.

Bacon, S., G. Reverdin, I. G. Rigor, and H. M. Snaith, 2002: A freshwater jet on the east Greenland shelf. J. Geophys. Res., 107, 3068, https://doi.org/10.1029/2001JC000935.

Bamber, J., M. Van Den Broeke, J. Ettema, J. Lenaerts, and E. Rignot, 2012: Recent large increases in freshwater fluxes from Greenland into the North Atlantic. Geophys. Res. Lett., 39, L19501, https://doi.org/10.1029/2012GL052552.

Bras, I. A.-A. L., F. Straneo, J. Holte, and N. P. Holliday, 2018: Seasonality of freshwater in the East Greenland Current system from 2014 to 2016. J. Geophys. Res. Oceans, 123, 88288848, https://doi.org/10.1029/2018JC014511.

Brink, K. H., 1982: The effect of bottom friction on low-frequency coastal trapped waves. J. Phys. Oceanogr., 12, 127-133, https:// doi.org/10.1175/1520-0485(1982)012<0127:TEOBFO >2.0.CO;2. , 2006: Coastal-trapped waves with finite bottom friction. Dyn. Atmos. Oceans, 41, 172-190, https://doi.org/10.1016/j.dynatmoce. 2006.05.001.

__ 2018: bigr*.m: Stable coastal-trapped waves with stratification, topography and mean flow in Matlab. Woods Hole Open Access Server Doc., 16 pp., https://doi.org/10.1575/ 1912/10527.

Bromwich, D. H., and Coauthors, 2018: The Arctic System Reanalysis, version 2. Bull. Amer. Meteor. Soc., 99, 805-828, https://doi.org/10.1175/BAMS-D-16-0215.1.

Bruce, J. G., 1995: Eddies southwest of Denmark Strait. Deep-Sea Res. I, 42, 13-29, https://doi.org/10.1016/0967-0637(94)00040-Y.

Buchwald, V. T., and J. K. Adams, 1968: The propagation of continental shelf waves. Proc. Roy. Soc. London, 305A, 235-250, https://doi.org/10.1098/rspa.1968.0115.

Caldwell, D. R., D. L. Cutchin, and M. S. Longuet-Higgins, 1972: Some model experiments on continental shelf waves. J. Mar. Res., 30, 39-55.

Clarke, A. J., 1977: Observational and numerical evidence for wind-forced coastal trapped waves. J. Phys. Oceanogr., 7, 231-247, https://doi.org/10.1175/1520-0485(1977)007<0231: OANEFW $>2.0 . \mathrm{CO} ; 2$.

Cummings, J. A., and O. M. Smedstad, 2013: Variational data assimilation for the global ocean. Data Assimilation for Atmospheric, Oceanic and Hydrologic Applications, Vol. II, 
S. K. Park and L. Xu, Eds., Springer, 303-343, https://doi.org/ 10.1007/978-3-642-35088-7_13.

Cutchin, D. L., and R. L. Smith, 1973: Continental shelf waves: Low-frequency variations in sea level and currents over the Oregon continental shelf. J. Phys. Oceanogr., 3, 73-82, https:// doi.org/10.1175/1520-0485(1973)003<0073:CSWLFV>2.0.CO;2.

Dale, A. C., J. M. Huthnance, and T. J. Sherwin, 2001: Coastaltrapped waves and tides at near-inertial frequencies. J. Phys. Oceanogr., 31, 2958-2970, https://doi.org/10.1175/15200485(2001)031<2958:CTWATA >2.0.CO;2.

Donlon, C. J., M. Martin, J. Stark, J. Roberts-Jones, E. Fiedler, and W. Wimmer, 2012: The Operational Sea Surface Temperature and Sea Ice Analysis (OSTIA) system. Remote Sens. Environ., 116, 140-158, https://doi.org/10.1016/j.rse.2010.10.017.

Fischer, J., and Coauthors, 2015: Intra-seasonal variability of the DWBC in the western subpolar North Atlantic. Prog. Oceanogr., 132, 233-249, https://doi.org/10.1016/j.pocean.2014.04.002.

Foukal, N. P., R. Gelderloos, and R. S. Pickart, 2020: A continuous pathway for fresh water along the East Greenland shelf. Sci. $A d v ., 6$, eabc4254, https://doi.org/10.1126/sciadv.abc4254.

Fraser, N. J., and M. E. Inall, 2018: Influence of barrier wind forcing on heat delivery toward the Greenland ice sheet. J. Geophys. Res. Oceans, 123, 2513-2538, https://doi.org/10.1002/2017JC013464.

,-- , M. G. Magaldi, T. W. Haine, and S. C. Jones, 2018: Wintertime fjord-shelf interaction and ice sheet melting in southeast Greenland. J. Geophys. Res. Oceans, 123, 91569177, https://doi.org/10.1029/2018JC014435.

Gelderloos, R., T. W. N. Haine, I. M. Koszalka, and M. G. Magaldi, 2017: Seasonal variability in warm-water inflow toward Kangerdlugssuaq Fjord. J. Phys. Oceanogr., 47, 1685-1699, https://doi.org/10.1175/JPO-D-16-0202.1.

Gill, A. E., and A. J. Clarke, 1974: Wind-induced upwelling, coastal currents and sea-level changes. Deep-Sea Res. Oceanogr. Abstr., 21, 325-345, https://doi.org/10.1016/0011-7471(74)90038-2.

Grinsted, A., J. C. Moore, and S. Jevrejeva, 2004: Application of the cross wavelet transform and wavelet coherence to geophysical time series. Nonlinear Processes Geophys., 11, 561566, https://doi.org/10.5194/npg-11-561-2004.

Haine, T. W. N., 2010: High-frequency fluctuations in Denmark Strait transport. Geophys. Res. Lett., 37, L14601, https:// doi.org/10.1029/2010GL043272.

Hamon, B. V., 1962: The spectrums of mean sea level at sydney, Coff's Harbour, and Lord Howe Island. J. Geophys. Res., 67, 5147-5155, https://doi.org/10.1029/JZ067i013p05147.

— 1963: Correction to 'The spectrums of mean sea level at Sydney, Coff's Harbour, and Lord Howe Island'. J. Geophys. Res., 68, 4635, https://doi.org/10.1029/JZ068i015p04635.

Harden, B. E., and R. S. Pickart, 2018: High-frequency variability in the North Icelandic jet. J. Mar. Res., 76, 47-62, https:// doi.org/10.1357/002224018824845910.

,-- , and I. A. Renfrew, 2014a: Offshore transport of dense water from the East Greenland shelf. J. Phys. Oceanogr., 44, 229-245, https://doi.org/10.1175/JPO-D-12-0218.1.

_- F. Straneo, and D. A. Sutherland, 2014b: Moored observations of synoptic and seasonal variability in the East Greenland Coastal Current. J. Geophys. Res. Oceans, 119, 8838-8857, https://doi.org/10.1002/2014JC010134.

— , and Coauthors, 2016: Upstream sources of the Denmark Strait Overflow: Observations from a high-resolution mooring array. Deep-Sea Res. I, 112, 94-112, https://doi.org/10.1016/ j.dsr.2016.02.007.

Håvik, L., R. S. Pickart, K. Våge, D. Torres, A. M. Thurnherr, A. Beszczynska-Möller, W. Walczowski, and W.-J. von
Appen, 2017: Evolution of the East Greenland Current from Fram Strait to Denmark Strait: Synoptic measurements from summer 2012. J. Geophys. Res. Oceans, 122, 1974-1994, https://doi.org/10.1002/2016JC012228.

_ - M. Almansi, K. Våge, and T. W. N. Haine, 2019: Atlantic-origin overflow water in the East Greenland Current. J. Phys. Oceanogr., 49, 2255-2269, do, https://doi.org/10.1175/JPO-D-18-0216.1.

Heimbach, P., D. Menemenlis, M. Losch, J. M. Campin, and C. Hill, 2010: On the formulation of sea-ice models. Part 2: Lessons from multi-year adjoint sea-ice export sensitivities through the Canadian Arctic Archipelago. Ocean Modell., 33, 145-158, https://doi.org/10.1016/j.ocemod.2010.02.002.

Huthnance, J. M., 1978: On coastal trapped waves: Analysis and numerical calculation by inverse iteration. J. Phys. Oceanogr., 8, 74-92, https://doi.org/10.1175/1520-0485(1978)008<0074: OCTWAA $>2.0 . \mathrm{CO} ; 2$.

Inall, M. E., F. Nilsen, F. R. Cottier, and R. Daae, 2015: Shelf/fjord exchange driven by coastal-trapped waves in the Arctic. J. Geophys. Res. Oceans, 120, 8283-8303, https://doi.org/ 10.1002/2015JC011277.

Jackson, R. H., F. Straneo, and D. A. Sutherland, 2014: Externally forced fluctuations in ocean temperature at Greenland glaciers in non-summer months. Nat. Geosci., 7, 503-508, https:// doi.org/10.1038/ngeo2186.

— S. J. Lentz, and F. Straneo, 2018: The dynamics of shelf forcing in Greenlandic Fjords. J. Phys. Oceanogr., 48, 27992827, https://doi.org/10.1175/JPO-D-18-0057.1.

Jochumsen, K., M. Moritz, N. Nunes, D. Quadfasel, K. M. H. Larsen, B. Hansen, H. Valdimarsson, and S. Jonsson, 2017: Revised transport estimates of the Denmark Strait overflow. J. Geophys. Res. Oceans, 122, 3434-3450, https://doi.org/ 10.1002/2017JC012803.

Johnson, E. R., and S. R. Clarke, 2001: Rossby wave hydraulics. Annu. Rev. Fluid Mech., 33, 207-230, https://doi.org/10.1146/ annurev.fluid.33.1.207.

Katsman, C. A., S. S. Drijfhout, H. A. Dijkstra, and M. A. Spall, 2018: Sinking of dense North Atlantic waters in a global ocean model: Location and controls. J. Geophys. Res. Oceans, 123, 3563-3576, https://doi.org/10.1029/2017JC013329.

Koszalka, I. M., T. W. N. Haine, and M. G. Magaldi, 2013: Fates and travel times of Denmark Strait overflow water in the Irminger Basin. J. Phys. Oceanogr., 43, 2611-2628, https:// doi.org/10.1175/JPO-D-13-023.1.

Lilly, J. M., 2019: jlab: A data analysis package for Matlab, v. 1.6.6. http://www.jmlilly.net/software.

Losch, M., D. Menemenlis, J. M. Campin, P. Heimbach, and C. Hill, 2010: On the formulation of sea-ice models. Part 1: Effects of different solver implementations and parameterizations. Ocean Modell., 33, 129-144, https://doi.org/10.1016/ j.ocemod.2009.12.008.

Magaldi, M. G., T. W. N. Haine, and R. S. Pickart, 2011: On the nature and variability of the East Greenland spill jet: A case study in summer 2003. J. Phys. Oceanogr., 41, 2307-2327, https://doi.org/10.1175/JPO-D-10-05004.1.

Marshall, J., A. Adcroft, C. Hill, L. Perelman, and C. Heisey, 1997: A finite-volume, incompressible Navier Stokes model for studies of the ocean on parallel computers. J. Geophys. Res., 102, 5753-5766, https://doi.org/10.1029/96JC02775.

Mooers, C. N. K., and R. L. Smith, 1968: Continental shelf waves off Oregon. J. Geophys. Res., 73, 549-557, https://doi.org/ 10.1029/JB073i002p00549.

Mysak, L. A., 1967a: On the theory of continental shelf waves. J. Mar. Res., 25, 205-227. 
, 1967b: On the very low frequency spectrum of the sea level on a continental shelf. J. Geophys. Res., 72, 3043-3047, https:// doi.org/10.1029/JZ072i012p03043.

_ 1980: Topographically trapped waves. Annu. Rev. Fluid Mech., 12, 45-76, https://doi.org/10.1146/annurev.fl.12.010180. 000401.

Nguyen, A. T., D. Menemenlis, and R. Kwok, 2009: Improved modeling of the arctic halocline with a subgrid-scale brine rejection parameterization. J. Geophys. Res., 114, C11014, https://doi.org/10.1029/2008JC005121.

Niiler, P. P., and L. A. Mysak, 1971: Barotropic waves along an eastern continental shelf. Geophys. Fluid Dyn., 2, 273-288, https://doi.org/10.1080/03091927108236063.

Noël, B., W. Jan Van De Berg, H. MacHguth, S. Lhermitte, I. Howat, X. Fettweis, and M. R. Van Den Broeke, 2016: A daily, $1 \mathrm{~km}$ resolution data set of downscaled Greenland ice sheet surface mass balance (1958-2015). Cryosphere, 10, 23612377, https://doi.org/10.5194/tc-10-2361-2016.

North, G. R., T. L. Bell, R. F. Cahalan, and F. J. Moeng, 1982: Sampling errors in the estimation of empirical orthogonal functions. Mon. Wea. Rev., 110, 699-706, https://doi.org/ 10.1175/1520-0493(1982)110<0699:SEITEO > 2.0.CO;2.

Pacini, A., and Coauthors, 2020: Mean conditions and seasonality of the West Greenland boundary current system near cape farewell. J. Phys. Oceanogr., 50, 2849-2871, https://doi.org/ 10.1175/JPO-D-20-0086.1.

Pawlowicz, R., B. Beardsley, and S. Lentz, 2002: Classical tidal harmonic analysis including error estimates in MATLAB using T-TIDE. Comput. Geosci., 28, 929-937, https://doi.org/ 10.1016/S0098-3004(02)00013-4.

Petersen, G. N., I. A. Renfrew, and G. W. K. Moore, 2009: An overview of barrier winds off southeastern Greenland during the Greenland Flow Distortion experiment. Quart. J. Roy. Meteor. Soc., 135, 1950-1967, https://doi.org/10.1002/qj.455.

Rhines, P., 1970: Edge-, bottom-, and Rossby waves in a rotating stratified fluid. Geophys. Fluid Dyn., 1, 273-302, https:// doi.org/10.1080/03091927009365776.

Robinson, A. R., 1964: Continental shelf waves and the response of sea level to weather systems. J. Geophys. Res., 69, 367-368, https://doi.org/10.1029/JZ069i002p00367.

Rodney, J. T., and E. R. Johnson, 2012: Localisation of coastal trapped waves by longshore variations in bottom topography. Cont. Shelf Res., 32, 130-137, https://doi.org/10.1016/ j.csr.2011.11.002.
— transformation of coastal-trapped waves. J. Phys. Oceanogr., 44, 1133-1150, https://doi.org/10.1175/JPO-D-12-0224.1.

_ and - 2015: Localised continental shelf waves: Geometric effects and resonant forcing. J. Fluid Mech., 785, 54-77, https:// doi.org/10.1017/jfm.2015.588.

Rudels, B., E. Fahrbach, J. Meincke, G. Budeéus, and P. Eriksson, 2002: The East Greenland current and its contribution to the Denmark Strait overflow. ICES J. Mar. Sci., 59, 1133-1154, https://doi.org/10.1006/jmsc.2002.1284.

Saberi, A., T. W. N. Haine, R. Gelderloos, M. F. de Jong, H. Furey, and A. Bower, 2020: Lagrangian perspective on the origins of Denmark Strait Overflow. J. Phys. Oceanogr., 50, 2393-2414, https://doi.org/10.1175/JPO-D-19-0210.1.

Sakov, P., F. Counillon, L. Bertino, K. A. Lister, P. R. Oke, and A. Korablev, 2012: TOPAZ4: An ocean-sea ice data assimilation system for the North Atlantic and Arctic. Ocean Sci., 8 , 633-656, https://doi.org/10.5194/os-8-633-2012.

Spall, M. A., and J. Pedlosky, 2018: Shelf-open ocean exchange forced by wind jets. J. Phys. Oceanogr., 48, 163-174, https:// doi.org/10.1175/JPO-D-17-0161.1.

—, R. S. Pickart, P. Lin, W.-J. V. Appen, D. Mastropole, H. Valdimarsson, T. W. N. Haine, and M. Almansi, 2019: Frontogenesis and variability in Denmark Strait and its influence on overflow water. J. Phys. Oceanogr., 49, 1889-1904, https://doi.org/10.1175/JPO-D-19-0053.1.

Thomson, D. J., 1982: Spectrum estimation and harmonic analysis. Proc. IEEE, 70, 1055-1096, https://doi.org/10.1109/ PROC.1982.12433.

Torrence, C., and G. P. Compo, 1998: A practical guide to wavelet analysis. Bull. Amer. Meteor. Soc., 79, 61-78, https://doi.org/ 10.1175/1520-0477(1998)079<0061:APGTWA > 2.0.CO;2.

von Appen, W.-J., R. S. Pickart, K. H. Brink, and T. W. N. Haine, 2014a: Water column structure and statistics of Denmark Strait overflow water cyclones. Deep-Sea Res. I, 84, 110-126, https://doi.org/10.1016/j.dsr.2013.10.007.

_ important component of the Atlantic Meridional Overturning Circulation. Deep-Sea Res. I, 92, 75-84, https://doi.org/ 10.1016/j.dsr.2014.06.002.

Wheeler, M. C., and H. H. Hendon, 2004: An all-season real-time multivariate MJO index: Development of an index for monitoring and prediction. Mon. Wea. Rev., 132, 1917-1932, https://doi.org/ 10.1175/1520-0493(2004)132<1917:AARMMI>2.0.CO;2. 